\title{
Preliminary Tritium Management Design Activities at ORNL
}

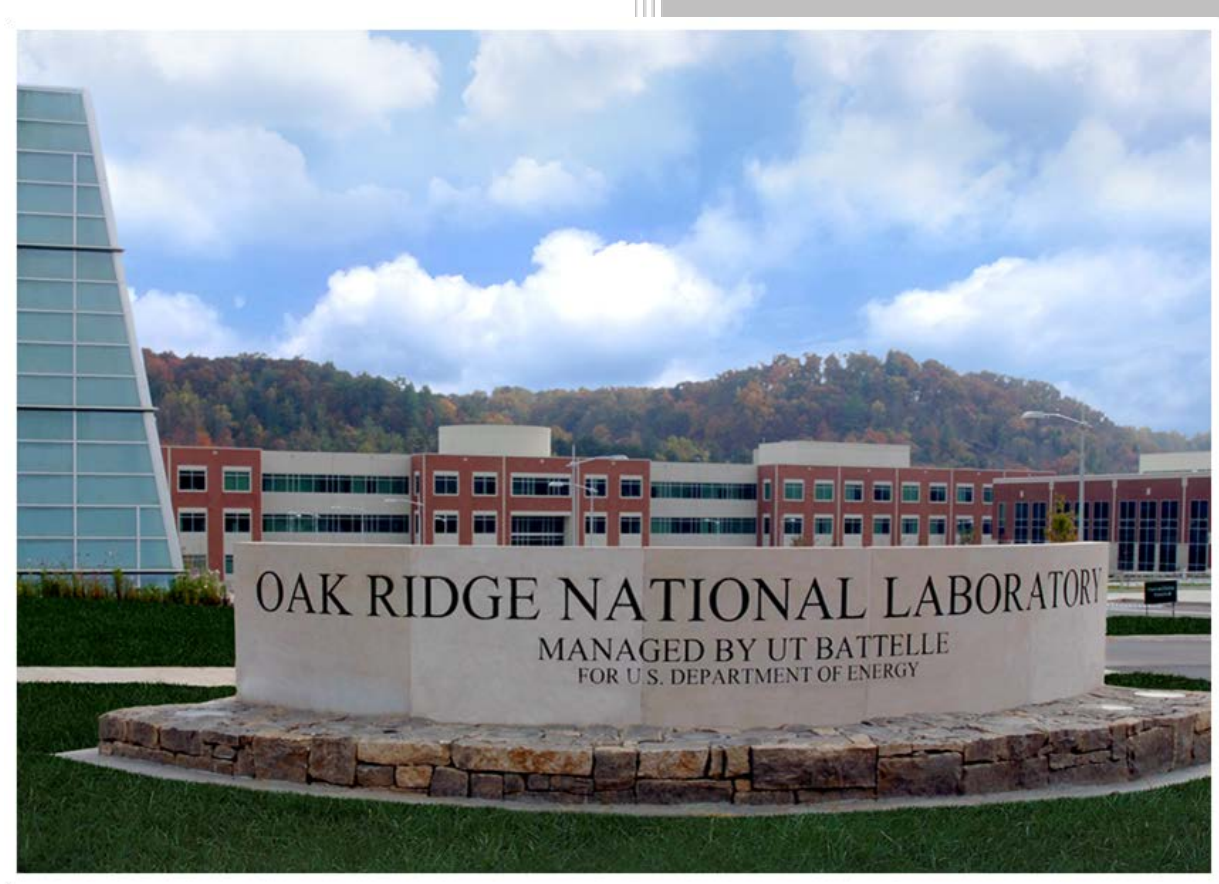

\section{Approved for public release. Distribution is unlimited.}
T. J. Harrison
D. K. Felde
R. J. Logsdon
J. McFarlane
A. L. Qualls

September 2016 


\title{
DOCUMENT AVAILABILITY
}

Reports produced after January 1, 1996, are generally available free via US Department of Energy (DOE) SciTech Connect.

\section{Website http://www.osti.gov/scitech/}

Reports produced before January 1, 1996, may be purchased by members of the public from the following source:

\author{
National Technical Information Service \\ 5285 Port Royal Road \\ Springfield, VA 22161 \\ Telephone 703-605-6000 (1-800-553-6847) \\ TDD 703-487-4639 \\ Fax 703-605-6900 \\ E-mail info@ntis.gov \\ Website http://www.ntis.gov/help/ordermethods.aspx
}

Reports are available to DOE employees, DOE contractors, Energy Technology Data Exchange representatives, and International Nuclear Information System representatives from the following source:

Office of Scientific and Technical Information

PO Box 62

Oak Ridge, TN 37831

Telephone 865-576-8401

Fax 865-576-5728

E-mail reports@osti.gov

Website http://www.osti.gov/contact.html

This report was prepared as an account of work sponsored by an agency of the United States Government. Neither the United States Government nor any agency thereof, nor any of their employees, makes any warranty, express or implied, or assumes any legal liability or responsibility for the accuracy, completeness, or usefulness of any information, apparatus, product, or process disclosed, or represents that its use would not infringe privately owned rights. Reference herein to any specific commercial product, process, or service by trade name, trademark, manufacturer, or otherwise, does not necessarily constitute or imply its endorsement, recommendation, or favoring by the United States Government or any agency thereof. The views and opinions of authors expressed herein do not necessarily state or reflect those of the United States Government or any agency thereof. 
Reactor and Nuclear Systems Division

PRELIMINARY TRITIUM MANAGEMENT DESIGN ACTIVITIES AT ORNL

\author{
T. J. Harrison \\ D. K. Felde \\ R. J. Logsdon* \\ J. McFarlane** \\ A. L. Qualls \\ *Nuclear Security and Isotope Technology Division \\ **Energy and Transportation Science Division
}

Date Published: September 2016

Prepared by

OAK RIDGE NATIONAL LABORATORY

Oak Ridge, TN 37831-6283

managed by

UT-BATTELLE, LLC

for the

US DEPARTMENT OF ENERGY

under contract DE-AC05-00OR22725 



\section{CONTENTS}

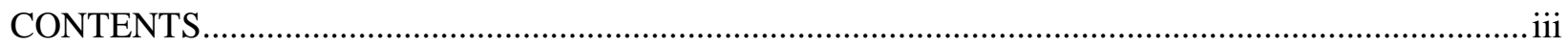

ACRONYMS

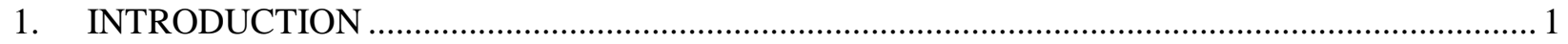

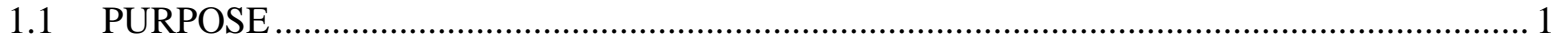

1.2 TRITIUM PRODUCTION IN SALT-COOLED AND SALT-FUELED REACTORS ............ 1

1.3 FLUORIDE SALTS AND THEIR PROPERTIES ...................................................... 1

1.4 TRITIUM GENERATION IN SALTS ........................................................................... 2

1.4.1 Sources of Tritium in Salt Coolants .......................................................................... 2

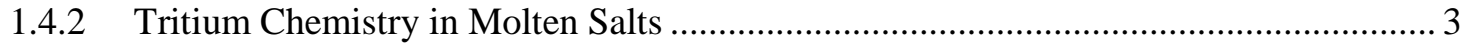

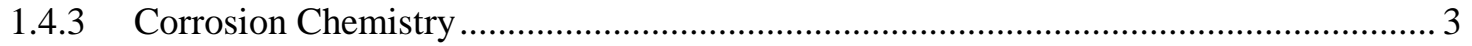

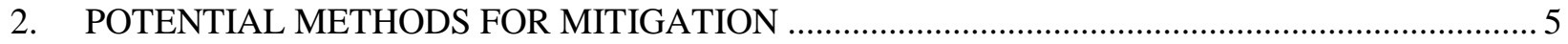

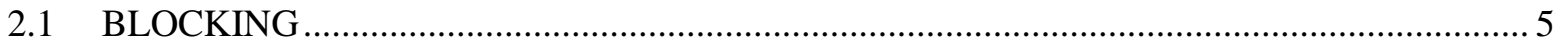

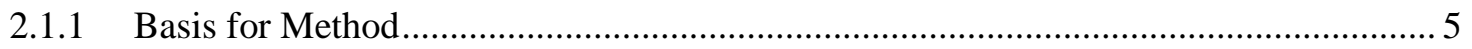

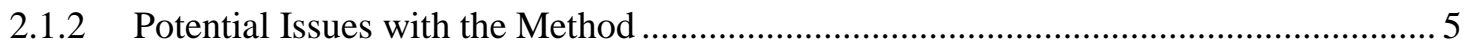

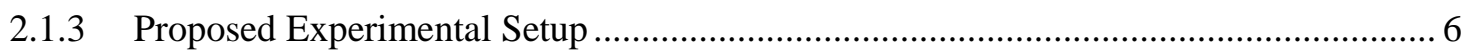

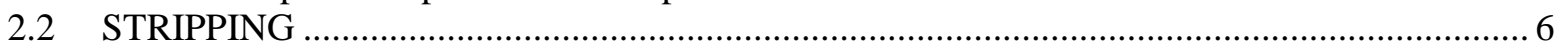

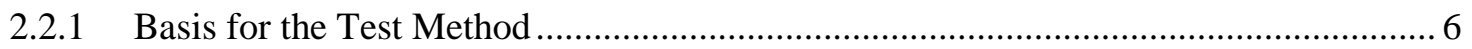

2.2.2 Potential Issues with the Test Method .................................................................... 7

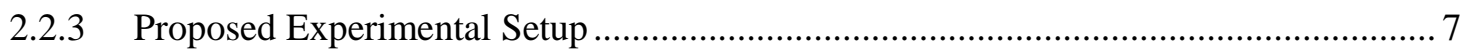

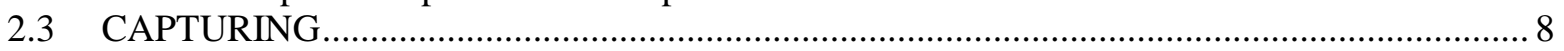

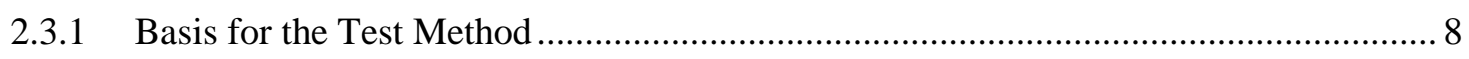

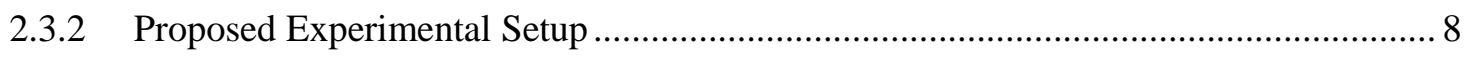

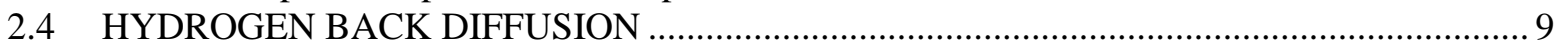

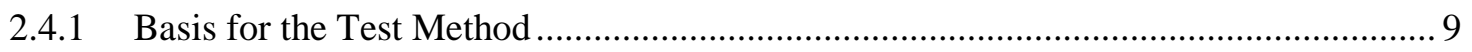

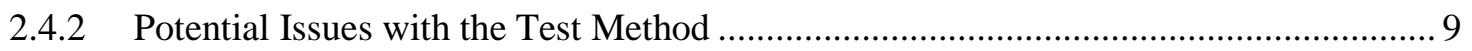

2.4.3 Proposed Experimental Set Up .......................................................................... 9

3. PRELIMINARY TRITIUM MANAGEMENT EXPERIMENTAL DESIGN efforts ........................ 11

3.1 REQUIREMENTS FOR GENERATING AND HANDLING SALT .................................... 11

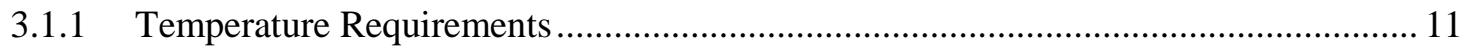

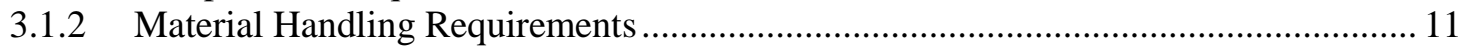

3.2 REQUIREMENTS FOR GENERATING AND HANDLING TRITIUM .............................. 12

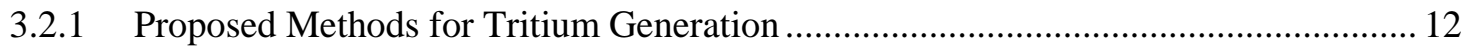

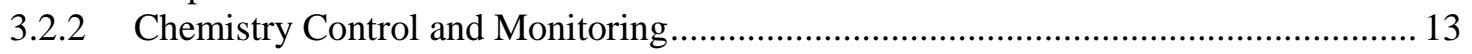

3.3 REQUIREMENTS FOR MEASURING THE EFFECTIVENESS OF TRITIUM

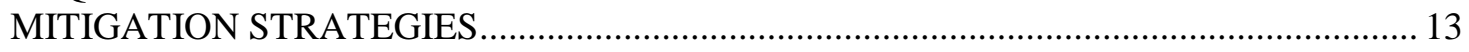

3.3.1 Tritium Collection and Quantification Methods, Limits, and Limitations .................. 13

3.4 REQUIREMENTS FOR PERFORMING EXPERIMENTS AT REPRESENTATIVE

TEMPERATURES, PRESSURES, AND FLOW RATES .................................................. 14

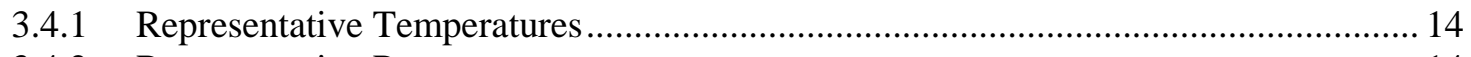

3.4.2 Representative Pressures..................................................................................... 14

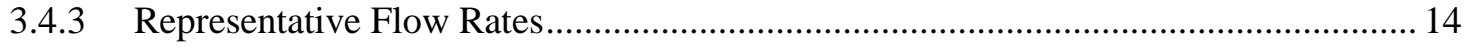

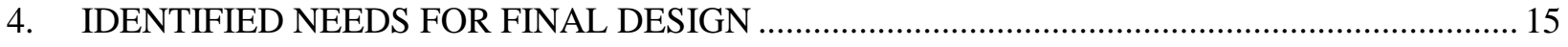

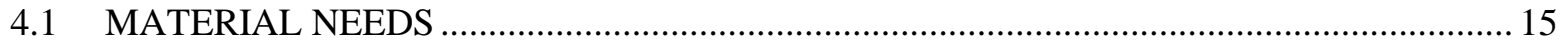

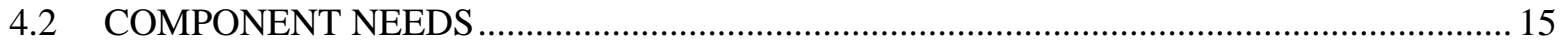

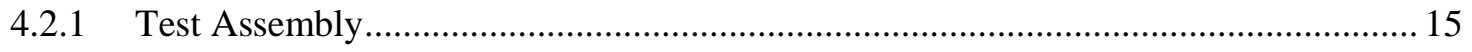

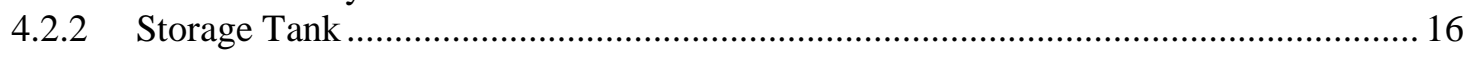

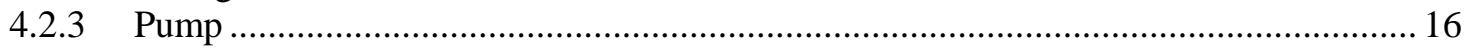




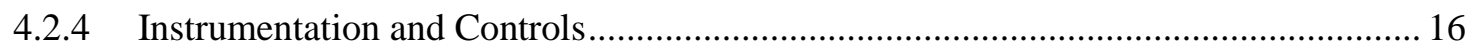

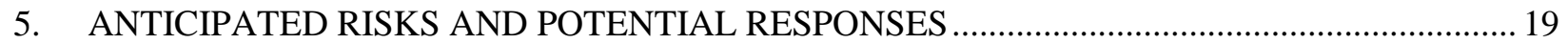

5.1 RISKS AND RESPONSES FOR THE EXPERIMENTAL SETUP …................................. 19

6. SUMMARY OF CURRENT DESIGN WORK AND PLAN FOR FUTURE WORK....................... 21

6.1 SUMMARY OF CURRENT DESIGN EFFORT .......................................................... 21

6.2 PLAN TO COMPLETE THE DESIGN AND BEGIN TESTING ….................................. 21

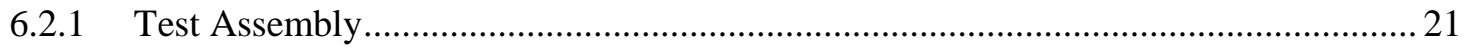

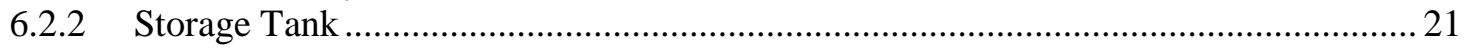

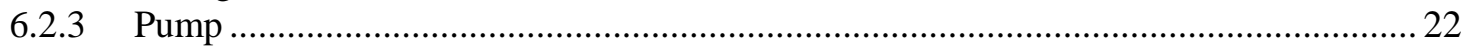

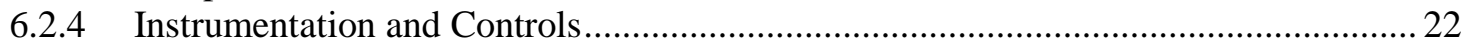

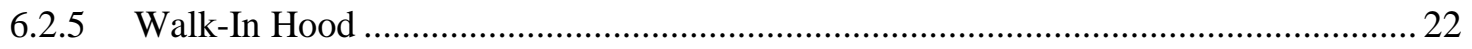

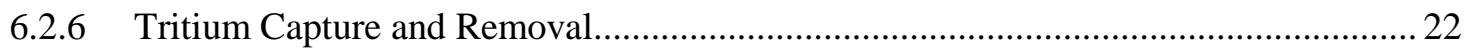

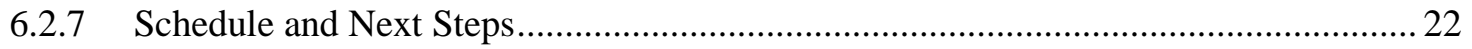

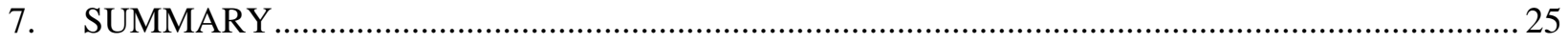

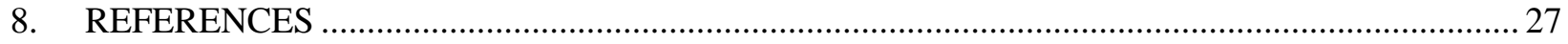

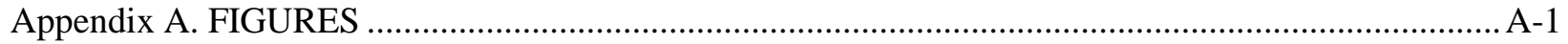

Figure 1. Walk-in hood similar to that proposed for tritium mitigation experiments...................... A-1

Figure 2. Femto-TECH ion chamber and controller................................................................... A-1

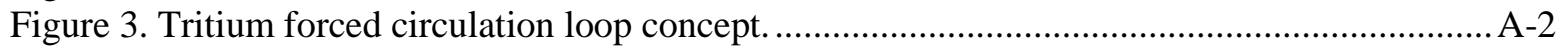

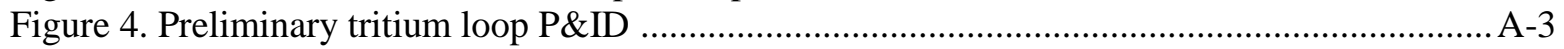

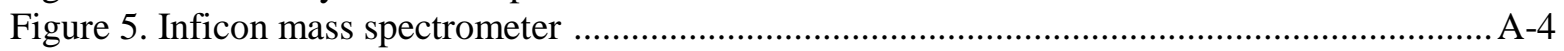

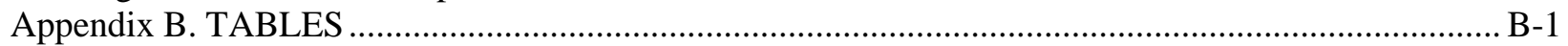

Table 1. Properties of fluorinated molten salts (Williams et al. 2006, Beneš and Konings, 2009)

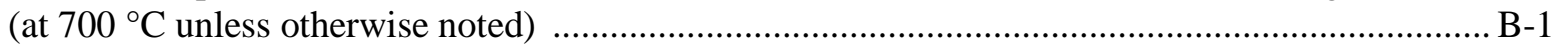

Table 2. Transmutation reactions in FLiBe molten salts ........................................................... B-2

Table 3. Permeability of tritium through selected materials (Christensen et al. 2016)..................... B-3

Table 4. Tritium permeation barriers (University of Wisconsin et al. 2013).................................. B-4

Table 5. U24-D control unit specifications ................................................................................ B-5

Table 6. Comparison of GB and PP flow through Femto-Tech ion chambers ............................. B-6

Table 7. Femto-TECH ion chamber system types, cost, and quantities ....................................... B-7

Table 8. Specifications for Inficon mass spectrometer .............................................................. B-8 


\section{ACRONYMS}

$\begin{array}{ll}\text { AHTR } & \text { advanced high-temperature reactor } \\ \text { CANDU } & \text { Canada deuterium-uranium } \\ \text { DOE } & \text { US Department of Energy } \\ \text { EEPROM } & \text { electrically erasable programmable read-only memory } \\ \text { FHR } & \text { fluoride-salt cooled high temperature reactor } \\ \text { FLIQURE } & \text { Fusion Liquid Release Experiment } \\ \text { HIF } & \text { heavy ion fusion } \\ \text { HTGR } & \text { high-temperature gas-cooled reactor } \\ \text { INEEL } & \text { Idaho National Environmental and Engineering Laboratory } \\ \text { INL } & \text { Idaho National Laboratory } \\ \text { IRP } & \text { Integrated Research Project } \\ \text { LLNL } & \text { Lawrence Livermore National Laboratory } \\ \text { MSBR } & \text { molten salt breeder reactor } \\ \text { MSR } & \text { molten salt reactor } \\ \text { MSRE } & \text { Molten Salt Reactor Experiment } \\ \text { NGNP } & \text { Next Generation Nuclear Plant } \\ \text { ORNL } & \text { Oak Ridge National Laboratory } \\ \text { PB-FHR } & \text { pebble bed FHR } \\ \text { P\&ID } & \text { piping and instrumentation diagram } \\ \text { PLC } & \text { programmable logic controller } \\ \text { PRF } & \text { permeation reduction factor } \\ \text { PVT } & \text { pressure volume temperature } \\ \text { R\&D } & \text { research and development } \\ \text { RWP } & \text { radiation work package } \\ \text { SBMS } & \text { Standards Based Management System } \\ \text { SEM } & \text { scanning electron microscopy } \\ & \end{array}$





\section{INTRODUCTION}

\subsection{PURPOSE}

Interest in salt-cooled and salt-fueled reactors has increased over the last decade (Forsberg et al. 2016). Several private companies and universities in the United States, as well as governments in other countries, are developing salt reactor designs and/or technology. Two primary issues for the development and deployment of many salt reactor concepts are (1) the prevention of tritium generation and (2) the management of tritium to prevent release to the environment (Holcomb 2013). In 2016, the US Department of Energy (DOE) initiated a research project under the Advanced Reactor Technology Program to (1) experimentally assess the feasibility of proposed methods for tritium mitigation and (2) to perform an engineering demonstration of the most promising methods. This document describes results from the first year's efforts to define, design, and build an experimental apparatus to test potential methods for tritium management. These efforts are focused on producing a final design document as the basis for the apparatus and its scheduled completion consistent with available budget and approvals for facility use.

\subsection{TRITIUM PRODUCTION IN SALT-COOLED AND SALT-FUELED REACTORS}

Salt-cooled reactors use solid fuel, including prismatic or pebble bed systems with unfueled salt cooling. In salt-fueled reactors, fuel is dissolved in the salt. These are two variants of the more general high temperature salt reactor class, and they are both referred to generically as molten salt reactors (MSRs). Both variants use high-temperature, low-pressure salt coolant. An MSR can refer to either a fluoride saltbased reactor or to a chloride salt-based reactor. This effort focuses on thermal fluoride salt reactors, which typically use a combination of lithium fluoride and beryllium fluoride salts, commonly referred to as FLiBe. When exposed to a neutron flux, FLiBe produces tritium regardless of whether the fuel resides in the salt or in a fixed fuel form. Tritium production occurs primarily through the ${ }^{6} \mathrm{Li}+\mathrm{n} \rightarrow{ }^{3} \mathrm{H}+{ }^{4} \mathrm{He}$ reaction; more details are given in Section 1.4. Any technological development that mitigates tritium release from fluoride salt is applicable to both salt-fueled and salt-cooled reactors.

\subsection{FLUORIDE SALTS AND THEIR PROPERTIES}

Molten salt chemistry has been studied extensively (e.g., Grimes 1967, 1970), as it affects a number of different nuclear technologies. Grimes’ 1958 analysis indicates which fluoride salts are the best candidate materials. These include alkali fluorides, $\mathrm{ZrF}_{4}$-salt mixtures, and $\mathrm{BeF}_{2}$-salt mixtures. Fluoride salt candidates and their physical and chemical properties have been reviewed by Williams et al. (2006) and Beneš and Koning (2009). Eutectic materials have the lowest melting points. Hence, the Williams et al. assessment included FLiBe, a $\mathrm{LiF}$ and $\mathrm{BeF}_{2}$ mixture with molecular ratio of 2:1 (Sawan and Sze 2003), and FLiNaK (46.5 mol\% LiF- 11.5 mol\% NaF- 42 mole\% KF). Although this is not the lowest melting point combination of $\mathrm{LiF}$ and $\mathrm{BeF}_{2}$, the viscosities of lower melting point materials are too high for practical use. As potassium has a larger thermal neutron capture cross section, potassium-containing salts are not considered as primary system fluids for thermal spectrum reactors. However, FLiNaK can serve as a secondary heat transfer fluid. The properties of FLiBe and FLiNaK fluoride salts are given in Table 1.

FLiBe has advantages of a relatively low melting point of $458-460^{\circ} \mathrm{C}$ and a high boiling point of approximately $1400^{\circ} \mathrm{C}$. FLiBe has low vapor pressure $\left(\sim 1 \mathrm{mbar}\right.$ at $\left.900{ }^{\circ} \mathrm{C}\right)$, and it exhibits roughly congruent evaporation, meaning that the vapor composition is the same as that of the liquid. In fluoridesalt cooled high temperature reactors (FHRs) FLiBe can be considered a single liquid phase under reactor operating conditions. 
Other advantages for FLiBe are that it has a high heat capacity, at $630{ }^{\circ} \mathrm{C}, \mathrm{Cp}=5.3 \mathrm{MJ} \cdot \mathrm{m}^{-3} \cdot \mathrm{K}^{-1}(0.642$ $\left.\mathrm{cal} \cdot \mathrm{g}^{-1} \cdot\left({ }^{\circ} \mathrm{C}\right)^{-1}\right)$, a low neutron absorption cross section, a high thermal conductivity with respect to other molten fluoride salts, and it is optically transparent. The density of FLiBe is high compared to water but low compared to a coolant such as liquid lead because of the light element constituents, and it decreases with temperature. Temperature expressions have been developed by Petit and Dulong (1819) for the heat capacities, yet they change little with temperature.

Fluid transport properties include viscosity, which, as these salts are Newtonian fluids, varies greatly with temperature. However, the molten salts generally have viscosities $<0.01 \mathrm{~Pa} \cdot \mathrm{s}$. Correlations developed at Oak Ridge National Laboratory (ORNL) and shown in Table 1 overestimate more recent measurements (e.g., Khokholv et al. 2009, Tørklep and Øye 1980) by roughly 20\%. FLiBe concentrations are typically fixed at a 2:1 composition because beryllium fluoride concentrations must be limited to less than $45 \mathrm{~mol} \%$ to prevent $\mathrm{BeF}_{2}$ self-association and consequent increased viscosity of the melt.

The review by Williams et al. (2006) states that measurements of thermal conductivity are difficult, and have led to erroneous conclusions in the literature regarding molten salt behavior. Williams recommended the model by Rao and Turnbull as being the most accurate, as shown in Equation (1) and outlined in the review by Cornwell (1971).

$$
k\left(\text { watt } \cdot m^{-1} \cdot K^{-1}\right)=0.119 \cdot T_{m}^{0.5} \cdot \rho^{0.667} \cdot\left(\frac{M}{n}\right)^{-1.167},
$$

where $T_{m}$ refers to melting point in $\mathrm{K}, \rho$ to molar volume in $\mathrm{cm}^{3} \cdot \mathrm{mol}^{-1}, M$ to the average formula weight $\left(\mathrm{g} \mathrm{mol}^{-1}\right)$, and $\mathrm{n}$ to the number of discrete ions per salt formula, which is generally set at 2 . This formula gives the same thermal conductivity values of 1.0-1.2 $\mathrm{W} \mathrm{m}^{-1} \mathrm{~K}^{-1}$ recommended by Beneš and Koning (2009).

Williams et al. (2006) also reviewed neutronics, neutron capture, and moderating capability. Values for these properties for FLiBe and FLiNaK are also given in Table 1.

\subsection{TRITIUM GENERATION IN SALTS}

\subsubsection{Sources of Tritium in Salt Coolants}

Relevant transmutation reactions are given in Table 2. Transmutation in lithium- and beryllium-bearing salts produce tritium (from ${ }^{6} \mathrm{Li}$ at early times, ${ }^{7} \mathrm{Li}$ and ${ }^{9} \mathrm{Be}$ at steady state). At equilibrium, a $410 \mathrm{MWe}$ pebble bed fluoride-salt cooled high temperature reactor (PB-FHR) is estimated to produce $93 \mathrm{TBq}(2,500$ $\mathrm{Ci}$ ) of tritium per day (University of Wisconsin et al. 2013). The greater the salt inventory, the longer it takes the PB-FHR to achieve equilibrium from a maximum and initial production rate of $\sim 666 \mathrm{TBq}$ (18 $\mathrm{kCi}$ ) per day. However, the amount of salt ultimately does not affect the equilibrium production rate of tritium for a given neutron source (University of Wisconsin et al. 2013). Other reactors where tritium is generated in significant quantities include the Canada deuterium-uranium (CANDU) reactors. The chemistry of tritium in a CANDU is different because of the $\mathrm{D}_{2} \mathrm{O}$-based coolant and moderator. Tritium produced within FLiBe has a different chemistry and life cycle within the cooling system, specifically involving reactions with primary loop surfaces.

Transmutation of a lithium in LiF releases the bonded fluorine with the production of tritium, and it will behave as the other fluorine in the melt, combining with tritium to give TF. The speciation of tritium in salt will depend on the redox conditions. Studies indicate that under normal operating conditions, the tritium is primarily in the form of TF ( $>95 \%)$. Transmutation yields depend on the neutron flux and 
spectrum as well as the material being irradiated. The cross sections for alpha and proton ejection are energy dependent and have thresholds.

Tritium production in an FHR is projected to range from 5000 to $500 \mathrm{Ci} / \mathrm{d}$ (185 to $18.5 \mathrm{TBq} / \mathrm{d})$ (Ingersoll et al. 2004). The preconceptual AHTR design has a FLiBe coolant flow rate of $5.54 \mathrm{~m}^{3} / \mathrm{s}$, which gives a tritium inventory of $2.2 \times 10^{16}$ to $10^{17}$ atoms of $\mathrm{T}$ per $\mathrm{m}^{3}$ per $\mathrm{s}$. As a comparison, calculations performed by Sawan and Sze (2003) give a tritium production rate in standard FLiBe fusion blanket materials as $1.42 \times$ $10^{18}$ atoms of $\mathrm{T}$ per $\mathrm{m}^{3}$ per s. Sawan and Sze also estimated the yields of less important transmutation processes that make oxygen at $7 \%$ of the rate of $\mathrm{T}$ breeding, and it makes nitrogen at $14 \%$ of the rate of $\mathrm{T}$ breeding in the same scenario.

\subsubsection{Tritium Chemistry in Molten Salts}

A free tritium atom moves through the molten salt until it meets a bonding partner. If it meets a free fluorine atom, it will form TF; this is soluble in the molten salt and migrates in this form, eventually reaching structural surfaces. In some cases hydrogen is introduced into the system, as will be discussed later in Section 2.4. If the tritium encounters a free hydrogen atom, it will form HT; this moves to structural surfaces. Both TF and HT interact with these structural surfaces, forming tritium or hydrogen atoms and $\mathrm{HT}, \mathrm{H}_{2}$, or $\mathrm{T}_{2}$. Tritium chemistry may also be affected by alloying elements in structural metals, as well as available oxygen impurities in the salt. In its reduced form as a diatomic gas, tritium has a reduced solubility in molten salts and will find preferential plating or diffusion sites on the structural surfaces. As atomic tritium, the transport through metals will be rapid at a rate depending on the partial pressure of $\mathrm{T}_{2}$ (Calderoni et al. 2008). Transport properties through various materials are shown in Table 3. While most of these data are from experiments with hydrogen, the FLiBe data were collected with tritium gas. Within the group of metals, penetration, permeability, diffusion, and absorption rates vary widely. For example, vanadium and niobium have high permeability with respect to tritium, while yttrium can form the tritide $\mathrm{YT}_{3}$ (Yannopoulos et al. 1973). Tritium penetration of nickel is actually lower than predicted by Sievert's law (Röhrig et al. 1975, Christensen et al. 2016). The diffusion rate of tritium through palladium is higher than any other metal.

If the tritium remains bound as TF, it will remain in the salt and will not diffuse through the metal. The rate-determining step for the release of $\mathrm{T}_{2}$ from the system is the migration of TF through the salt to a structural surface. Once TF reaches a metal surface, it may decompose, and the high solubility of tritium in the metal allows it to escape the reactor cooling system. Permeabilities through FLiBe, FLiNaK, and various metals are given in Table 3. The diffusion of tritium species is expected to increase in the reactor environment, assisted by a high level of neutron and gamma irradiation (Avila et al. 2010).

\subsubsection{Corrosion Chemistry}

Because tritium forms TF in the coolant, much of the interest in tritium chemistry has been its effect on structural materials. Calderoni et al. (2009) reviewed the literature pertaining to corrosion chemistry. Oxygen from moisture and oxide impurities, and oxygen atoms resulting from the transmutation of ${ }^{19} \mathrm{~F}$ (Table 2) can accelerate corrosion. Corrosion has been observed in 316 stainless steel and ferritic /martensitic (400 series) steels. The redox state of corrosion products will depend on the chemical potential of each of the chemical species present, whether introduced as salt, through transmutation and the radiation environment, reactions with contacting materials, or as the gaseous environment. For instance, FLiBe may contain chromium (II), iron (II) and Ni (II), whereas FLiNaK will have more oxidized chromium (III) and some iron (III), as well as iron (II). 
Tritium corrosion chemistry depends on the chemical potentials of free $\mathrm{F}$ and TF. Non-fluorinated beryllium in the blanket and heat transport loop can be used to reduce TF and $\mathrm{F}_{2}$ to $\mathrm{BeF}_{2}$ and $\mathrm{T}_{2}$, as shown in Reaction (1). A kinetic model is available from Simpson et al. (2006). Beryllium can be introduced as solid metal or as carbide for tritium chemistry control. Only as much beryllium as needed for redox control should be added. An excess of beryllium may react with graphite, which can accelerate the corrosion process (Wu et al., 2016). Also, the amount of beryllium that should be added will be limited by resulting effects on the viscosity of the fluid (Williams et al. 2006). Other materials introduced as alloys or salt components can reduce corrosion by TF, such as metallic reoxidants $\mathrm{Zr}$ or Na.

$$
\mathrm{Be}+2 \mathrm{TF} \rightarrow \mathrm{BeF}_{2}+\mathrm{T}_{2}
$$




\section{POTENTIAL METHODS FOR MITIGATION}

Tritium can penetrate metals, which is problematic in the primary-to-intermediate loop heat exchanger, as the heat exchanger has a large surface area at high temperature for efficient movement of tritium across the metal barrier. The Ohio State University reviewed tritium mitigation and control in a test loop (Wu et al. 2016) along with the proposed control methodologies that are candidates for investigation. Although a number of different mitigation technologies can be used, it is likely that a combination of them will be necessary.

Ultimately, the goal of a tritium mitigation strategy is to limit the environmental release in MSRs to levels below regulatory limits. Tritium control starts with redox chemistry (discussed in more detail in Section 4.2.2) to facilitate the chosen mitigation method.

\subsection{BLOCKING}

Penetration barriers are coatings applied to permeable metallic structures to reduce the escape of $T_{2}$ from the system. Such barriers have been developed for tritium storage, along with getter or absorbing materials. Barrier materials and other technologies have been reviewed by Savannah River National Laboratory (Sherman and Adams 2008).

\subsubsection{Basis for Method}

Tritium penetration of heat exchangers can be problematic because of the exchangers' high temperatures and large surface areas. Applying a barrier coating, often a ceramic, can reduce $\mathrm{T}$ and $\mathrm{T}_{2}$ diffusion and impede corrosion of the base metal. Heat exchanger barriers can be applied to the surface of the metal, or they can be made in situ by reactions with the fluids. The barriers can be located on the hot or cold side of the heat exchanger, a function of the chemical and physical compatibility of the barrier material and the fluid.

Examples of coatings are given in Table 4. For instance, $\mathrm{Al}_{2} \mathrm{O}_{3}$ (soluble in FLiBe) and $\mathrm{SiC}$ barriers have been used to reduce the diffusivity of $\mathrm{T}$ atoms (Weaver and Wall 2007). These solid ceramic barriers have the lowest tritium penetration, which is better than that of bare metal by a factor of $10^{7}-10^{8}$. Other external barriers include $\mathrm{Cr}_{2} \mathrm{O}_{3} / \mathrm{SiO}_{2}$ and layered TiN/TiC/SiO 2 . (Sherman and Adams 2008) In situ formed oxide coatings can protect the high temperature Inconel and Incoloy alloys used in heat exchangers. These barriers reduce tritium penetration from the base alloy by factors of 200-1,000. Tritium permeation increases with temperature.

The effectiveness of a permeation barrier is expressed as a permeation reduction factor (PRF) that is the ratio of the permeation flux through a material without a coating to one with a coating. Hence, the ratio should be greater than one for an effective barrier. The effectiveness depends on the thickness of the barrier, defects in the barrier and/or the underlying structural material, fracture toughness and exposure to thermal and mechanical shocks, hydrogen partial pressure, and the compatibility of thermal expansion throughout the layers of material.

\subsubsection{Potential Issues with the Method}

Barriers are difficult to manufacture, as they involve adhesion of dissimilar materials, and they may not survive repeated heat cycling. This is particularly true of the ceramic layers that do not have the selfhealing capability of the oxides. Placing the barrier material on the non-molten salt side of a containment structure can reduce chemical compatibility concerns and increase lifetimes. Processes are being 
developed to adhere alumina coatings to steel substrates to make them more heat resistant (Hubert et al. 2006). These efforts may prove beneficial to blocking tritium, as well.

\subsubsection{Proposed Experimental Setup}

The permeation barrier will be chosen based on the ability to apply a coating of the material to the metallic surface in a way that can be repeated and the ability of the coating to withstand salt chemistry. Well-adhered alumina coatings can be prepared reliably using sol-gel methods (Wang et al. 2016). Alumina has a fairly high PRF, ranging from 100-10,000, depending on a thickness ranging from 0.031.4 micron, respectively. However, alumina itself could not be used to block tritium migration from one salt loop to another as it is soluble in FLiBe. Such a coating would be used on an exterior loop surface to reduce tritium losses and act to reduce variability and provide experimental control for mass balance measurements and their related calculations.

Tests must be conducted to quantify the thickness and reproducibility of the coating on representative components before the actual apparatus being tested can be treated. Macroscopic cracking and peeling may be observable by optical microscopy, and scanning electron microscopy (SEM) may be used to observe smaller defects. PRF values would be recorded using ion chamber measurements for coated and uncoated pieces, which are identical in every other respect. Repeated measurements could be taken after coated material is exposed to heat, molten salt (if applicable), and variable tritium partial pressures. The variable tritium partial pressures are used to simulate the effect of radiative fluence as an additional impacting parameter.

As tritium loss occurs largely in the region of the heat exchanger, various representative heat exchanger arrangements would be evaluated in the test facility, some of which have already been outlined in Wu et al. (2016). In these tests, mass transfer must be considered, along with heat transfer. Restrictions on flow imposed by highly tortuous pathways will also affect the flow of the molten salt; hence, pressure drop and variations in salt flow rate are also important variables.

\subsection{STRIPPING}

An inert sweep gas can be used to remove tritium from molten salt by capturing $T_{2}$ that has escaped into a surrounding envelope, or it can be bubbled directly through the molten salt itself. Depending on the stripping technology being studied, the gas could be sparged through the molten FLiBe salt directly, passed through a secondary salt loop, or be circulated through an annular gap in a primary loop or secondary loop structure.

Getters have been developed for tritium storage after being stripped from the salt. For instance, tritium from CANDU reactors is extracted from heavy water and stored as tritium gas absorbed on titanium metal. Note that as titanium is soluble in the molten salt, such a sponge would need to be used in an assembly that is not in direct contact with the salt itself.

\subsubsection{Basis for the Test Method}

The passage of an inert gas through a tritiated molten salt can remove tritium based on minimization of the concentration gradient across the interface. Within the salt, inert gases can be injected into the primary and intermediate circuits to draw off $\mathrm{HT}$ and $\mathrm{T}_{2}$ (Briggs and Korsmeyer 1970). As an example, the Molten Salt Reactor Experiment (MSRE) had NaF-sodium fluoroborate as an intermediate coolant. Tritium has a high solubility in NaF-sodium fluoroborate. After being trapped in the intermediary salts, the tritium was then removed with a gas purge (Mays et al. 1977, Thoma 1972). Counterflow, in which the salt comes from the top and helium bubbling comes from the bottom through a packed column, can be 
used to effectively sweep out tritium dissolved in the molten salt (Fukada et al. 2006). Selectively permeable barriers that allow the passage of only tritium can be used to remove tritium from an annular gap.

For tritium removal using a sweep gas, high mass transfer and low heat transfer are required. This is in contrast to the requirements of a penetration barrier, in which high heat transfer and low mass transfer are being sought. Movement of tritium through a medium (fluid or solid), or permeability, depends on the product of diffusivity and solubility. In general, closed Brayton cycles are better able to provide tritium isolation than steam or open-air systems because the secondary side can use gases with low tritium solubility for separation, or in-flow tritium absorbers for direct tritium collection. Higher pressures allow for the use of smaller removal systems.

\subsubsection{Potential Issues with the Test Method}

Previous experience using sparging has identified issues with the method for tritium removal, primarily related to flow of the salt through the nozzles. MSRE tests showed that sparging will increase the cost and complexity of the reactor (Briggs and Korsmeyer 1970). For instance, helium sweep gas must be heated to the temperature of the salt before it is introduced into the facility; otherwise, the flow of high thermal conductivity gas will cool the salt mixture. However, the helium is rapidly heated by the salt (very low heat capacity compared to the salt) and then left hot as it is reused multiple times. Gas bubbling flow rates are limited to partial pressures below which bubbles coalesce, resulting in a reduction in surface area. The maximum flow rate is typically less than 20 vol\% (Wu et al. 2016).

The use of a sweep gas in combination with a permeation window is a slow process because tritium partial pressures are low, and transport through the salt to the extraction site requires turbulent flow (Fukada and Mitsuishi 1988).

Another method to accelerate mass transfer during stripping uses disengagers, proposed for FLiBe in a Tokamak fusion reactor, and tested at ORNL (Talbot 1976). To enhance mass transfer in this configuration, salt was sprayed through the disengagers, forming small droplets in a sweep gas of helium. High jet velocities were required to engineer the nozzles to obtain small droplet sizes without plugging. However, the nozzle orifices still experienced corrosion.

Experimental conditions are difficult to control when measuring tritium removal in a sweep gas. Tritium diffuses through vessel walls, so calculations of solubility, diffusivity, and permeability require careful control of experimental variables. The ratio of the vessel's surface area to its volume will affect the results, as well as the geometrical aspects of the sweep gas (i.e., helium) flow, as seen in finned plate experiments (Fraas and Özişik 1965).

\subsubsection{Proposed Experimental Setup}

As suggested by Fukada (2006), sweep gas mitigation of tritium removal can be tested in a packed column through a tritium-separating membrane (Holcomb and Wilson 2016) or in a permeation window extraction facility. Although any of these configurations may be tested in the laboratory, it is likely that the experimental facility planned here will focus on the tritium-separating membrane (Holcomb and Wilson 2016).

The extraction of tritium in the first case is comparable to chromatography, where the amount of tritium removed from the salt can be calculated based on theoretical plates of liquid- and gas-phase mass transfer. In the case of the membrane, the salt is either directed to contact the membrane or to pass through it. The tritium passes through the palladium-bearing layer and is allowed to come into contact with sweep gas 
that passes through the porous support. The sweep gas (e.g., helium) is not directly in contact with the FLiBe. Instead, it only comes into contact with the separated tritium. Palladium has a high affinity for hydrogen and so will allow tritium to penetrate. A drawback to palladium is its cost, so Pd membranes must be made as thin as possible. The third method-the extraction of tritium through a permeable barrier - depends on the behavior of tritium according to Henry's law, or the ratio of the gas phase partial pressure to the tritium concentration in the liquid phase.

Measurement of the sweep gas's efficacy could be studied by using a sponge material such as titanium or graphite. The absorber would be introduced directly into the sweep gas flow path as packing material after the separation of tritium. The absorption of tritium on getters can be monitored online using downstream monitors or a mass spectrometer. Getter materials used in the latter capacity can increase the sensitivity of tritium release detection methods.

To achieve good tritium mass balance, sweep gas methods should be combined with penetration barriers (see Section 3.1) to reduce losses through surfaces outside those of specific interest.

\subsection{CAPTURING}

\subsubsection{Basis for the Test Method}

A solid getter such as carbon can be employed to retain tritium within the primary system. These materials will include components of the loop, such as the graphitic fuel. However, control of tritium release will be achieved using external getter assemblies. Carbon might be employed with pebble bed reactor designs that also use graphite fuels (Cao 2013), as its introduction would not add new materials into the reactor primary system. Potential Issues with the Test Method

Absorbent materials are limited in capacity, and their absorption depends on temperature. A key part of getter efficacy is knowing when the sorbent capacity is being approached-practically at lower levels than full saturation of the getter material — and then substituting or regenerating to maintain functionality and thus control over tritium release. The properties of some materials are well known. For instance, carbon absorbs tritium at $700{ }^{\circ} \mathrm{C}$, but it will release tritium at $900{ }^{\circ} \mathrm{C}$. However, methods to regenerate the getter material must be included in the study of sorptive capacity, and conditions resulting in the release of tritium (such as reactor over-temperature events) must be understood.

As in the case of sweep gas systems, the capture efficiency of getters depends on the partial pressure of tritium. When tritium concentrations are high in the salt, the removal process is more efficient because concentration gradients are also high. However, the capture may use only a small feed of the coolant into a subsystem that includes getter materials. The process may take multiple loop passes to ensure that the entire inventory has been scrubbed. Hence, the rate of the capturing process must exceed that of tritium leakage from the primary circuit.

\subsubsection{Proposed Experimental Setup}

In this set up, the goal is to place a gettering material directly into the molten salt itself. The absorption of tritium on getters can be quantified by sampling the material for captured tritium over a long experiment or by formation of metal tritides (Gainey 1976). Graphite may comprise part of the fuel for FHRs, so tests should be performed with graphite in situ in the molten salt to determine its effect on tritium hold-up and release. As with other getter materials, entrained graphite will have a limited capacity for tritium, and it will affect the overall tritium release profile. Graphite-salt mass ratios must be characterized along with relative surface areas to allow quantification of bed hold-up times and release rates. 


\subsection{HYDROGEN BACK DIFFUSION}

A hydrogen diffusion strategy has been proposed for MSRs in which a circulating secondary salt loop takes heat from an independent primary salt loop. The flow of salt in the secondary loop passes by a heat exchanger to a steam circuit. The hydrogen back diffusion method to mitigate tritium ingress to the steam circuit imposes a hydrogen pressure within the secondary salt loop (Lecocq 1974).

\subsubsection{Basis for the Test Method}

The hydrogen added to the secondary salt loop will saturate the salt and then back-diffuse from the secondary salt to the primary salt. At the interfaces of the metal wall in between the primary and secondary loops, dissociation of $\mathrm{H}_{2}$ will occur. The hydrogen atoms generated at the interface will interact with the tritium atoms being made in the primary loop. The high partial pressure of hydrogen will prevent tritium from passing into the secondary circuit. A sweep gas circuit is added to the primary loop to remove tritium, excess hydrogen, and other volatile elements. The sweep gas is helium. The flow rate of hydrogen introduced into the secondary side is 600 times the flow rate of tritium.

\subsubsection{Potential Issues with the Test Method}

As proposed in the patent, one issue with the method is that it requires an intermediate salt loop, although common to almost all the designs, lowers the efficiency of power production. Another issue is that a pressure of $1 \mathrm{~atm}$ of hydrogen is required to saturate the secondary salt loop, so hazards associated with handling hydrogen must be considered in the apparatus design.

\subsubsection{Proposed Experimental Set Up}

To test this method, a second salt loop must be engineered into the apparatus design. The salt loop would operate independently of the first, requiring its own pump and piping. A hydrogen cylinder could be incorporated into the design, allowing a steady flow of hydrogen through the second molten salt loop, similar to that proposed for the helium sweep gas mentioned in Section 2.2. 



\section{PRELIMINARY TRITIUM MANAGEMENT EXPERIMENTAL DESIGN EFFORTS}

Details concerning the requirements for the salt, the tritium generation and chemistry, and the instrumentation are given in this section.

\subsection{REQUIREMENTS FOR GENERATING AND HANDLING SALT}

Clean FLiBe salt must be prepared for the experiments. The constituent salts $\mathrm{LiF}$ and $\mathrm{BeF}_{2}$ are readily available from commercial sources, but the eutectic mixture will require a melt process and a purification process to remove oxygen, moisture, and other contaminants.

An activity under a university-led Integrated Research Project (IRP) at ORNL is under way to build a FLiBe purification facility to provide high purity salt for corrosion studies at partner universities (Georgia Institute of Technology 2014). This capability can be leveraged for the production of FLiBe for this project. A laboratory in Building 4505 at ORNL is being refurbished to accommodate the purification facility. Loops for the tritium management project will also be located in this laboratory, which will allow the projects to share space and equipment, thereby reducing costs.

Salt purification primarily to remove oxides is necessary to reduce corrosion and deposition of solids (Shaffer 1971). The salt purification process includes (1) weighing and mixing the constituent salt compounds, $\mathrm{LiF}$ and $\mathrm{BeF}_{2}$, in the correct portions, (2) loading the salt mixture into a graphite-lined vessel, (3) melting the salt mixture, (4) bubbling hydrogen fluoride and hydrogen gas through the melt in a prescribed sequence to purify, and (5) purging with Ar gas and cooling down/solidifying the salt. A glovebox for handling the Be-containing salt and an existing fume hood are used to control Be contamination and any potential exposure to flammable and hazardous gases used in the process. The first two steps are performed in the glovebox, while steps 3-5 are performed in the fume hood. The laboratory space is described in more detail in Section 4.2.

The salt purification system is designed to produce $\sim 4 \mathrm{~kg}$ batches of FLiBe. It takes $\sim 12$ days to produce the high purity level salts needed for corrosion testing. It may not be necessary to have this level of purity for the tritium management experiments, so the length of the process could be shortened to reduce labor cost and time commitment. The facility is scheduled to be approved and qualified for the production of the first batch of FLiBe salt for a Georgia Institute of Technology project (Georgia Institute of Technology 2014) to be conducted in the spring of 2017. There are no further commitments of the facility beyond production of one batch of FLiBe for the IRP, so it is projected that purified salt could be available for tritium testing by the summer of 2017.

\subsubsection{Temperature Requirements}

The nominal design operating temperature for the relevant MSR designs is $700{ }^{\circ} \mathrm{C}$. Electrical heating capacity will allow the experiment to operate $\sim 100^{\circ} \mathrm{C}$ above this temperature. The melting point of the FLiBe salt is $\sim 459{ }^{\circ} \mathrm{C}$. The purification process is conducted at nominally $600{ }^{\circ} \mathrm{C}$.

\subsubsection{Material Handling Requirements}

Salt containing Be requires special handling to prevent personnel exposure and the spread of contamination. The salt is toxic and also has specific Be hazards. It requires gloves for handling in the cold condition, as well as appropriate respiratory protection. Procedures for working with beryllium are outlined in the ORNL Standards Based Management System (SBMS) (Petherick 2015). Work with the FLiBe salt will be performed in gloveboxes or hoods. For transfer of materials out of the laboratory, Be 
surveys will be required on containers/packages with the potential for Be contamination. Colocation of the tritium experiments with the purification facility is a significant advantage because it minimizes the need for surveys when transferring salts between the two sets of equipment.

For tritium experiments, salt will generally be transferred in the molten condition via transfer tubes between vessels using dip tubes and gas overpressure to move the salt. These processes will be conducted in either the purification process fume hood or in a walk-in fume hood similar to that shown in Figure 1. Specifically, salt would be transferred from the purification process vessel into the tritium loop experiment storage tank via this method. Alternatively, purified salt would be collected in a secondary transfer tank depending on the number of batches of purified salt required. The storage and transfer tanks will be designed to accommodate cooldown and melting of the salt without damaging the vessel. Opening vessels containing salt (i.e., installation of a transfer tube) will require inert gas purging to prevent introduction of air/moisture into the salt. Opening of salt-containing vessels or piping in the cold condition will be performed in the glovebox whenever possible under the inert (argon) atmosphere.

ORNL has well-established procedures for working with Be and Be-containing materials, and these will be incorporated into work practices in the lab (Baes 1965, Keiser et al. 1977, Keiser 1977, and World Health Organization 1990).

\subsection{REQUIREMENTS FOR GENERATING AND HANDLING TRITIUM}

\subsubsection{Proposed Methods for Tritium Generation}

The feasibility of generating the tritium in situ within FLiBe using an external neutron source was assessed. In calculations for fusion blankets (Sawan and Sze 2003), the amount of free tritium produced under steady state conditions is $7 \times 10^{10}$ atoms per $\mathrm{cm}^{3}$ per s. Assuming two liters of salt, the conversion to molecules of TF per $\mathrm{m}^{3}$ per s would be $2.66 \times 10^{15}$, leaving $1.4 \times 10^{14}$ atoms of free tritium. The total amount of tritium corresponds to $4.7 \times 10^{-9} \mathrm{~mol}$ in $2 \mathrm{~L}$ FLiBe, or 14 nanograms/s at steady state. With a specific activity of $1066 \mathrm{TBq} / \mathrm{mol}(28,800 \mathrm{Ci} / \mathrm{mol})$, the steady-state tritium activity at these concentrations in $2 \mathrm{~L}$ FLiBe is $5 \mathrm{MBq}(135 \mu \mathrm{Ci})$.

An available $111 \mathrm{GBq}$ (3 Ci) AmBe neutron source was evaluated to determine if it could produce a useable tritium loading in the salt. A design study at Idaho National Laboratory (INL) on a proposed Fusion Liquid Release Experiment (FLIQURE) provided a useful reference in estimating tritium production on a FLiBe volume similar to that proposed for these studies (Sterbentz et.al. 2000). The 111 $\mathrm{GBq}$ (3 Ci) AmBe source produces $6.6 \times 10^{6}$ neutrons/s, a factor of 3,640 less than the Cf source proposed for use in the FLIQURE experiment design. ${ }^{1}$ The concentration of tritium in the salt in FLIQURE was projected to be $1.74 \times \times 10^{11}$ atoms $/ \mathrm{cm}^{3}$ after $20 \mathrm{~h}$ of irradiation, which in the $1,000 \mathrm{~cm}^{3}$ of salt gave $\sim 1.7 \times 10^{14}$ tritium atoms. For the $3 \mathrm{Ci}$ AmBe source, using a linear ratio of neutrons/s yields $4.7 \times 10^{10}$ tritium atoms in $2 \mathrm{~L}$ salt or $85.1 \mathrm{~Bq}\left(2.3 \times 10^{-9} \mathrm{Ci}\right)$; a factor of $\sim 6 \times 10^{4}$ lower than needed to simulate chemistry in the reactor. Hence, the loop cannot usefully produce tritium in situ and will require the addition of tritium from an external supply.

\footnotetext{
${ }^{1}$ The neutron spectra of the source and the reactor are different, so extrapolating tritium production depends on reflector/shielding design, etc. The $10 \mathrm{mg}$ Cf source evaluated for the proposed FLIQURE experiment in 2000 is not currently feasible due to cost and availability.
} 


\subsubsection{Chemistry Control and Monitoring}

Tritium in the form TF best represents the speciation in the molten salt coolant. Conversion of tritium to $\mathrm{T}_{2}$ limits corrosion and facilitates recovery in a sweep gas system. Therefore, this conversion is where much of the effort into chemistry control has been focused. Chemistry control is as important to tritium management as developing engineered barriers or getters.

Beryllium can be added to FLiBe to increase the ratio of $\mathrm{T}_{2}$ to $\mathrm{TF}$ either as a metal (powder or rod) or as a carbide. This has the advantage of not affecting the chemical or physical properties of the molten salt (Abe et al. 2008, Petti et al. 2006), and the consumption rate is relatively slow (Wu et al. 2016). In systems flushed with hydrogen, as the partial pressure of $\mathrm{H}_{2}$ increases, HT is more thermodynamically stable than $\mathrm{TF}$ and can also drive the conversion to the diatomic gas.

In the tritium management experiment loops, the tritium will initially be purchased as $T_{2}$ from a supplier. However, to reproduce tritium chemistry in the salt, the fluoride chemical potential, and thus tritium speciation, must be established upstream of the salt. Manipulation of tritium chemistry by enhancing the mole fraction of beryllium in the salt is also possible. To change tritium speciation, gas mixtures of $\mathrm{T}_{2} / \mathrm{H}_{2} / \mathrm{HF}$ will be equilibrated to form $\mathrm{T}_{2} / \mathrm{HT} / \mathrm{H}_{2} / \mathrm{HF} / \mathrm{TF}$ to replicate a predetermined fluoride chemical potential. The gas that passes through the system will be monitored with ion gauges for overall tritium release. The gas will also be monitored by mass spectroscopy to discern the ratios of $\mathrm{T}_{2} / \mathrm{H}_{2} / \mathrm{TH} / \mathrm{TF} / \mathrm{HF}$ before and after it passes through the process equipment. Thus, the overall radioactivity transfer and the chemical profile of the tritium can be monitored with time.

\subsection{REQUIREMENTS FOR MEASURING THE EFFECTIVENESS OF TRITIUM MITIGATION STRATEGIES}

\subsubsection{Tritium Collection and Quantification Methods, Limits, and Limitations}

Tritium will be monitored for safety and to quantify the effectiveness of capture and sweep mitigation strategies.

For quantifying the effectiveness of capture and mitigation overall, a mass balance of tritium will be prepared in the experimental apparatus. The amount of tritium put into the system will be known by gas handling measurements such as flow rates and partial pressures. The tritium in various segments will be assessed after the experiment using post-test examination and analysis. Online measurements of tritium activity will be taken in a sweep gas, if used. The mass spectrometer will allow determination of the tritium chemistry before and after passing through the molten salt and the capture/mitigation process unit.

Tritium handling will be conducted in a walk-in hood (Section 4.1). Both the hood/flow path and the room will be equipped with ion chambers. The femto-TECH 224 model ion chamber has a sensitivity of $3.7 \mathrm{kBq} / \mathrm{m}^{3}\left(0.1\right.$ microcurie $\left.\cdot \mathrm{m}^{-3}\right)$. The companion control unit (U24-D) specifications are given in Table 5, and the units and electronic controller are shown in Figure 2. Either a perforated (224DU) or pumped (224GB) design can be used for different applications. The pumped unit can be swaged into a closed system for online analysis. The perforated counter is used if a pump is not available, as for room monitoring. These instruments are used by the Lawrence Livermore National Laboratory (LLNL) Tritium Facility. For monitoring of the stack, LLNL also uses femto-TECH equipment, as shown in Table 6. 


\subsection{REQUIREMENTS FOR PERFORMING EXPERIMENTS AT REPRESENTATIVE TEMPERATURES, PRESSURES, AND FLOW RATES}

\subsubsection{Representative Temperatures}

Reaction kinetics and tritium penetration rates are strongly dependent on temperature, and the test loop must be operated at representative design temperatures for MSRs using FLiBe. The primary-tointermediate heat exchangers operate near the highest temperature $\left(\sim 700^{\circ} \mathrm{C}\right)$, have thinner walls, and more surface area than the reactor vessel, which operates at approximately $600{ }^{\circ} \mathrm{C}$. They are therefore more susceptible to tritium egress. Temperatures up to $800^{\circ} \mathrm{C}$ may be studied to simulate outside of normal operating conditions.

\subsubsection{Representative Pressures}

Loop operating pressure will be limited by pump design and sealing limitations. The salts themselves will have negligible vapor pressures. The pressure of the system will be controlled with an inert cover gas. This gas system will also be used to facilitate the movement of liquid salts into and out of the system and needs only to be sufficient to prevent ingress of outside air and to maintain a flow of tritium-fluorine gas into the salt (1-2 bar). The inert gas proposed for use in most salt reactors is argon. However, the test loop fill gas has not yet been selected, and helium may be preferable as a sweep gas. The selection of gases and their partial pressures will be determined by thermodynamics, the desired fluorine chemical potential, the permeability of the respective gases through barriers, and the salt medium itself. These aspects are discussed in Section 2.2.

\subsubsection{Representative Flow Rates}

One of the prime mechanisms for liberation of tritium is the interaction of TF with the wall material. Providing a representative boundary layer, as well as mixing effects and distribution of chemical species, may be important in characterizing tritium production and migration. Therefore, it was decided to incorporate forced convection in the experiment. Salt flow velocities in reactor concepts are limited by design to from 4-20 m/s. This value limits pressure drops in the system and may also be important in limiting corrosion. The targeted peak test loop flow velocity is $4 \mathrm{~m} / \mathrm{s}$. However, the flow velocity is to be variable down to the lowest velocities possible.

Methods of measuring or estimating flow rate within test sections will be required. A commercially available ultrasonic flow meter is currently installed on the FLiNaK salt loop at ORNL, although it has not yet been operated with flowing salt. A separate flow calibration stand for evaluation of this flow meter has also been built. Results from the calibration tests will be completed before operating the tritium loop experiment. Redundant and diverse flow measurements are desired. 


\section{IDENTIFIED NEEDS FOR FINAL DESIGN}

Tritium mitigation will be examined under the conditions expected in an FHR, but at a laboratory-scale. The conceptual design for a small forced circulation loop is shown in Figure 3. A cantilever centrifugal pump installed in a sump tank provides flow through a test section that will contain test materials for characterizing tritium interactions and migration. A storage tank located at the bottom of the loop provides salt to the loop via a dip tube. The loop shown is sized to accommodate a single $4 \mathrm{~kg}$ batch of purified salt ( 2 liters). However, the loop volume will likely be increased as the pump and test section requirements are incorporated into the final design.

\subsection{MATERIAL NEEDS}

The salt-wetted components in the loop will most likely be fabricated from Inconel 600. For the limited run time of a test assembly, this material is expected to perform satisfactorily. ORNL's FLiNaK salt loop was fabricated from Inconel 600, and this material has worked well to date. Weld procedures and fabrication methods are established for this material (Special Metals Corporation 2008).

Hastelloy ${ }^{\mathrm{TM}} \mathrm{N}$ was the preferred material in the MSRE era (Williams et al. 2006), but that material is not readily available in pipe or tube form without ordering a cost-prohibitive quantity. Other high nickel content materials may be considered. Hastelloy C276 has high nickel content and has shown good resistance to HF (Osbourne et al. 2002). This may be advantageous when high TF concentrations are used in the test.

Small tubing lines used for injection of TF or HF will be made from high nickel content tubing or from nickel alloy 200, Inconel 600, or Hastelloy C276. Compression fittings are available from Swagelok in Hastelloy C276 or Inconel 600, although lead times are long. Gas vent lines from the system with the potential for carrying TF or HF will also be fabricated from high nickel content material and heated to prevent possible condensation in the line.

The remainder of the tubing and fittings will operate at a lower temperature and can be made from 316 stainless steel as they are not wetted by the salt.

\subsection{COMPONENT NEEDS}

The major components of the proposed flow loop are described below. Of these, the pump poses the greatest challenge in terms of design and procurement/fabrication. With the exception of the tritium removal apparatus, the other components are relatively straightforward, and experience from the FLiNaK salt loop at ORNL can be leveraged in the design and fabrication processes.

\subsubsection{Test Assembly}

The test section shown in Figure 3 is proposed as a nested pipe/tubing arrangement with a flange on top to allow installation of test materials into the assembly. An addition tube is located in the center of the assembly to allow for the possibility of adding tritium gas into the flow stream via permeation of the tubing wall. The addition tube method is described in the report "Coolant Salt Technology Facility" (Mays et.al. 1977). A nickel diffuser disk located at the end of a dip tube may also be used (Calderoni 2008, Fukada and Morisaki 2006, Zeng 2014).

Material being tested for tritium management can be installed between the inner gas addition tube and the outer wall, most likely in an annular geometry. 
The salt-wetted components will mostly be welded. Flange connections may be necessary for the connection to the pump casing. Additional penetrations will be made for thermocouple welds and sample ports on the various components.

Although not shown in Figure 3, segmented containment enclosures will be installed around the test section and piping legs to allow a sweep gas to collect tritium that permeates through the high temperature wall boundary. The segmented enclosures will allow more detailed information on tritium migration from various parts of the flow loop (test section region, etc.).

\subsubsection{Storage Tank}

A storage tank to contain the salt in the cold condition is located at the bottom of the loop. A dip tube connects the tank to the loop. After melting the salt in the tank, argon gas overpressure is used in the tank to push the salt up into the loop. The salt level may be maintained by controlling the storage tank head space pressure via gas mass flow controllers on the gas supply and vent lines. This method has been used successfully in the FLiNaK loop. Alternatively, a freeze valve could be employed in the dip tube line between the storage tank and the test section. This has the advantage of disconnecting the storage tank volume and surface area from the flow loop when tracking the tritium migration. This assumes that the permeability of the frozen salt is relatively low compared to the metal walls of the flow loop.

\subsubsection{Pump}

A high temperature pump that is compatible with FLiBe salt is required for the flow loop. A cantilever centrifugal pump is depicted in Figure 3 where the impeller and volute/casing are submerged in a sump tank. This type of design allows an inert cover gas over the free surface of the salt. A long cantilever shaft allows the seals and bearings to be located in cooler regions that are removed from the high temperature salt in the sump tank.

Although details are not shown in Figure 3, a pump of this type was fabricated at ORNL for the FLiNaK salt loop. This pump has a nominal flow rate of $138 \mathrm{~L} / \mathrm{min}(36 \mathrm{gpm})$ with a developed head of $0.125 \mathrm{MPa}$ (18 psi) and impeller diameter of $14.29 \mathrm{~cm}$ (5.625 in.). However, this is too large for the tritium loop envisioned here. Using the pump affinity laws and making a $1 / 2$-scale version of this pump would provide $69 \mathrm{~L} / \mathrm{min}$ (18 gpm) with a head of $31.25 \mathrm{kPa}$ (4.5 psi). The existing pump was mostly built in house based on designs from a vendor that did not complete the project, so there is some uncertainty associated with scaling the pump. The shaft and bearing/seal support column must be shortened for this application in order to fit in the walk-in hood. The seals have worked well so far on the existing pump, although operating hours are somewhat limited at this time.

An alternative approach is to work with a pump manufacturer to develop a pump to meet the specific requirements of the loop. Several companies have developed high-temperature pumps for other applications, although not necessarily for fluorinated salts at this temperature. Information is available on small pumps developed during the earlier molten salt work at ORNL. An ALPHA pump is described in a system description for a corrosion test loop (Huntley 1976) that is in the correct size range. A pump bowl

combined the sump tank and casing in a compact form that is advantageous for this application. However, it used oil-cooled bearings, which are not ideal.

\subsubsection{Instrumentation and Controls}

A preliminary piping and instrumentation diagram (P\&ID) for the proposed flow loop is shown in Figure 4. Process instrumentation will include measurement gauges for pressure, flow, and temperature. Pressure measurements will be made in gas lines or from gas head spaces in the sump tank, storage tank, 
and test section assembly. Direct measurement of pressure in the salt is not planned. An ultrasonic flow meter similar to that used in the FLiNaK salt loop at ORNL is proposed.

An Allen Bradly Controllogix system will be used for loop control and data acquisition. Procurement and assembly of the instrumentation cabinet and associated hardware can be leveraged with the purification system project and will result in considerable cost savings.

Ion chambers and a mass spectrometer are proposed for measuring tritium in sweep gas, as well as constituent composition of the gas stream. A valve arrangement will be used to measure various gas streams from the loop. These instruments are described in more detail below.

\subsubsection{Thermal management}

Heater blanket and trace heaters will be used to heat the system to operating temperatures. The system will use solid state relay power control on individual heater zones. Control software logic that was developed using the Controllogix system for the FLiNaK salt loop will be used. This logic can control temperature ramp rates and steady state temperatures on an individual basis and per heater zone, and it can set programmed ramp/soak heat-up and cool-down profiles. The system is readily expandable, with each new heater zone requiring only a circuit breaker and solid-state relay.

\subsubsection{Ion chambers for tritium measurement}

Room monitoring and sample line measurement for tritium concentration will be required (DOE 2007). Ion chambers have been identified from a vendor with ranges as low as 0 to $74 \mathrm{MBq} / \mathrm{m}^{3}$ ( 0 to $2 \mathrm{mCi} / \mathrm{m}^{3}$ ) and a resolution of $3.7 \mathrm{kBq} / \mathrm{m}^{3}\left(0.1 \mu \mathrm{Ci} / \mathrm{m}^{3}\right)$. Accuracy is stated as $\pm 10 \%$ of reading. A standard femtoTECH monitoring system costs $\$ 15,570$ ( $\$ 20,000$ with overhead). Each system includes an ion chamber, a U24-D control unit, a 6-foot interconnecting cable, a power cord, an instruction manual, and quality assurance documents. Instrumentation requirements for the ion chamber for loop research and development (R\&D), room monitor, and fume hood stack monitoring are listed in Table 7 and would cost about $\$ 80,000$.

\subsubsection{Mass spectrometer}

A relatively inexpensive mass spectrometer is the CPM compact process monitor made by Inficon and provided by Triangle Vacuum in Raleigh, North Carolina. The quadrupole mass spectrometer costs between $\$ 55,000-75,000$, depending on configuration. The unit can sample gases at atmospheric pressure even though the quadrupole must operate at high vacuum. A schematic is provided in Figure 5 . The Inficon unit is used by the semiconductor industry for corrosive gas mixtures, and it is machined of 316 stainless steel, so it should be able to handle the application of tritium $/ \mathrm{TF} / \mathrm{F}_{2}$. Specifications are given in Table 8. 



\section{ANTICIPATED RISKS AND POTENTIAL RESPONSES}

\subsection{RISKS AND RESPONSES FOR THE EXPERIMENTAL SETUP}

The experimental setup for tritium management will require handling of tritium, $\mathrm{HF}, \mathrm{H}_{2}, \mathrm{~F}_{2}$, and Be all potentially at high temperatures. Each of these will require individual mitigation strategies, including special training and personnel qualifications similar to those required for radiation workers. Prior to introducing tritium into the system, the apparatus will not require radiation work package (RWP) approval as is required for initial pump and flow testing. Primary concerns when introducing tritium into the system are with the Be and HF handling for initial salt generation and purification activities. All environmental, health, and safety issues will be flowed into relevant safety documentation defined in SBMS. Specific hazards associated with the experiment include the following:

- Tritium: up to $144 \mathrm{GBq}$ (3.9 Ci) or $0.4 \mathrm{mg}$ per experiment;

- Beryllium: $\mathrm{BeF}_{2}$ component of FLiBe salt mixture, 2:1 LiF:BeF ${ }_{2}$-estimates are $200 \mathrm{~g}$ beryllium per liter of salt;

- HF: a small amount to modify the chemistry of the tritium introduced to the salt, e.g., 9:1 molar ratio $\mathrm{HF}: \mathrm{T}_{2}$;

- $\mathrm{H}_{2} / \mathrm{HF}$ mixture used to purify the salt before and after experiments; and

- High operating temperature of the experiment (up to $\sim 800^{\circ} \mathrm{C}$ ).

The experiment will be well instrumented, with a tritium monitor inside the walk-in hood where the experiments will be conducted and on the effluent of the hood. Radiation physics personnel have stated that only a tritium room monitor (local alarm only) would be required for personnel safety. However, a hydrogen detection monitor must be installed in the room for fire safety. An HF monitor will be needed for the stack. If the HF monitor, the $\mathrm{H}_{2}$ monitor, or the tritium room monitor should alarm, then any flow occurring through the experimental apparatus must shut off, and measures must be taken to minimize exposure of personnel to these gases. Exhaust fan failure or ventilation shutdown will trigger the same measures.

Periodic beryllium contamination smears will be performed to monitor contamination levels within the lab. $\mathrm{BeF}_{2}$ in solid form will be handled within a glovebox in the lab to mix with the $\mathrm{LiF}$ and will be heated to generate FLiBe salt. Once mixed, the heated beryllium salt will not be handled directly by personnel, but post-test sectioning and examination on cooled and archived samples will be performed. Once cooled, the $\mathrm{BeF}_{2}$ will not be in powder form. This project will share many of the same chemical and material handling requirements as the related salt purification project (Georgia Institute of Technology 2014) so that the hazard identification and mitigation efforts performed for the purification project can be leveraged.

A release of $3.7 \mathrm{TBq}(100 \mathrm{Ci})$ of tritium per year has been evaluated against the threshold limits established in the National Environmental Policy Act. This would include about 25 separate experiments, well beyond the anticipated activity level. Therefore, this is an upper bound to the release.

Solid waste will include piping, salt, and personal protective equipment. Liquid waste will include neutralized HF solutions from salt purification before and after the experiments. Tritium contamination of the solids and liquids must be assumed once introduced into the apparatus.

Training requirements will be determined from the research safety summary envelope. The laboratory will be operated under the ORNL standard. This will ensure that training includes requirements like reading the ORNL Chemical Hygiene Plan. Work with tritium will necessitate Radworker II training. Other training, such as beryllium handling, will also be required. 
The experiment will involve heating the salt to temperatures above $800^{\circ} \mathrm{C}$. However, power requirements of about $10 \mathrm{~kW}$ can be delivered to electrical heaters on a 120 or $240 \mathrm{~V}$ service.

Sources for tritium for the experiment are being investigated. 


\section{SUMMARY OF CURRENT DESIGN WORK AND PLAN FOR FUTURE WORK}

\subsection{SUMMARY OF CURRENT DESIGN EFFORT}

A conceptual design has been developed that defines the basic components of the forced convection loop, along with nominal dimensions and associated fluid volumes. This includes a representative test assembly with a nested component design that will accommodate test materials, as well as a means for injecting $\mathrm{T}$, $\mathrm{TF}$, and other constituents. A sampling system for measurement of $\mathrm{T}$ and other constituents in the effluent gas line and from permeation through primary pressure boundaries is also included. Details of the tritium capture or separations technologies to be tested are not complete.

A general concept for the pump is proposed that uses a cantilever centrifugal pump design. The key feature is a long shaft assembly that allows location of the seals and bearings away from the high temperature zone. A larger pump of this type has been built and operated in the FLiNaK salt loop at ORNL, and one option is to build a scale version of this pump. A more suitable option may be to work with a pump manufacture to develop a high temperature pump of the appropriate size.

A preliminary P\&ID was developed that identifies key process measurement and controls. This allows sufficient information for specification of analog and digital modules for the Allen Bradley Controllogix Programmable Logic Controller (PLC) system and general requirements for the associated instrument cabinet. The heater control cabinet that will include solid-state relays and circuit breakers for individual heater zones will be modelled after similar cabinets on the existing FLiNaK salt loop. The design is essentially complete except for defining the final number of heater zones.

Special instrumentation - the ion chambers and mass spectrometer-have been identified, and preliminary cost numbers have been received. The detailed connection arrangement for these instruments and interface with the process instrumentation and data acquisition system has not been completed.

\subsection{PLAN TO COMPLETE THE DESIGN AND BEGIN TESTING}

The detailed design for the loop is driven by specification of pump fluid volume requirements and available pump head, as well as tritium detection capability. This information, along with cost/schedule limitations on obtaining purified salt (number of $4 \mathrm{~kg}$ batches needed), will determine loop tubing size and storage tank capacity requirements. Detailed designs of the test assembly, the loop tubing configuration, and the storage tank can be completed following this pump specification process. Plans for the design of major components/systems are described in more detail below.

\subsubsection{Test Assembly}

Detailed drawings, including applicable weld specifications, will be completed for the test assembly. Development of specific test matrices will serve as guidance for detailed design of test materials and the gas/constituent injection method if continuous injection is required. The additional tube described previously that relies on permeation of a metal tube for tritium injection will not work for TF or HF injection, so alternative methods such as a capillary tube must be used.

\subsubsection{Storage Tank}

The detailed design of the storage tank will be completed with ports for the dip tube, gas supply, and gas vent lines. An insulator base and heating blanket will be procured. Figure 3 shows the basic design. The height can be modified to accommodate the actual salt volume in the final design. 


\subsubsection{Pump}

A pump size and the associated liquid volume in the sump tank/casing will be determined early in the process so that design criteria for the remainder of the loop components can be established. The preferred approach is to work with a pump manufacturer to develop and build a high-temperature pump. This will include specification of seals and bearings compatible with the cover gas above the liquid level in the pump's sump tank/casing. Alternatively, a scale version of the pump design used in the FLiNaK salt loop could be designed and built.

\subsubsection{Instrumentation and Controls}

A tabulation of instrumentation and control components will be completed. Associated wiring details will be developed for wiring and configuration of the instrument cabinet. Procurement of Controllogix PLC hardware, power supplies, terminal blocks, etc., will be made in the near term to take advantage of cost savings for the instrument cabinet that will be shared with the purification system project. Field wiring to the loop and system components will be made near the end of the loop fabrication and installation process.

The heater control cabinet design will be based on a similar design for the FLiNaK salt loop and can be ready for fabrication with minimal design effort.

Detailed design of the tritium/gas effluent sampling system will be completed. This will define procurement requirements for ion chambers (number, range, etc.) based on effluent gas flow rates and expected composition. Specification of the mass spectrometer and procurement will also be completed.

\subsubsection{Walk-In Hood}

A walk-in hood has been specified. A purchase order for this long lead item will be placed soon to ensure that it is available for installation in the Room 26 lab in the first quarter of FY17 as part of the laboratory refurbishment.

\subsubsection{Tritium Capture and Removal}

Final design of the tritium capture and removal assembly will depend on the priorities for testing as established by the FHR program. The assembly will be designed to be incorporated into the molten salt loop. Online and offline analyses of tritium will be planned, depending on the configuration and parameters for capture. The test apparatus - particularly if incorporated into the molten salt itself as suggested for some of the capture technologies - may be used only once and then sent for post-test analysis. Other assemblies will benefit from several tests involving a range of flow rates, capture times, and pressures, such as those involving gas diffusion or sparging. The final design of the first test assembly will depend on available budget and final loop commissioning.

\subsubsection{Schedule and Next Steps}

The schedule will largely depend on funding levels and the availability of the purified FLiBe salt from a separate project. It is expected that the salt will not be available until the summer of 2017. Priorities of key schedule components in relation to funding availability are discussed below.

The development of the pump for the forced convection loop should be a high priority funding and schedule item. Development of the pump is expected to take 8-9 months, with a projected cost of $\$ 150,000$ based on preliminary discussions with an outside vendor. An alternative in-house development 
would cost at least as much and would carry more risk. Early characterization of the pump is needed to define flow velocity, loop salt volume, and loop sealing interfaces.

Detailed design of the test section and loop would follow next in scheduling priority. The detailed design of the T/TF injection methods and features for collection and sampling of the tritium leaving the system is a key aspect of the design. Development of specific test matrices and test articles/methods for tritium management will be needed to define design requirements.

Preparation of the lab space is expected to occur in the first quarter of FY17. Completion of the lab walkin hood installation and connection of the associated utilities is expected to be completed by the end of the second quarter in FY17. Although preparation of the lab space will be covered under an ORNL infrastructure improvement project, some project costs will be incurred in setting up room monitoring associated with tritium and beryllium handling and the walk-in hood installation. There will be some relatively high cost components, such as ion chambers for tritium measurement and the mass spectrometer required for actual tritium operations. These items can be procured later in the schedule within their prospective lead times since their function is well known.

The PLC and data acquisition system instrument cabinet will be completed by the end of the first quarter of FY17 in a joint effort with the purification system project. Combining these efforts will allow for considerable cost savings. Once the detailed test section and loop design are completed, the final process instrumentation and controls requirements can be defined. The field instrumentation and components for the loop can be procured later in the schedule. 



\section{SUMMARY}

Salt reactors using lithium-bearing fluoride salts will generate significant amounts of tritium in the primary system. This tritium may migrate from the primary system, into and through the secondary system, and into power conversion system and then the environment. Successful design, development, and deployment of salt reactors will require methods to prevent, mitigate, or manage tritium production and migration through the system. An experimental loop to test potential tritium management methods is being designed at ORNL. The loop will produce representative temperature, chemistry, and flow conditions in an MSR and will allow for the injection of tritium into the salt. Procurement and/or development of components needed for the loop are currently under investigation, and the appropriate laboratory space, relevant safety documents, and procedures are being prepared in conjunction with appropriate safety and regulatory subject matter experts. With adequate resources, it is expected that the loop will be operational in FY18. 



\section{REFERENCES}

Abe, K., Kohyama, A., Tanaka, S., Namba, C., Terai, T., Kunugi, T., Muroga, T., Hasegawa, A., Sagara, A., Berk, S., Zinkle, S.J., Sze, D. K., Petti, D. A., Abdou, M. A., Morley, N. B., Kurtz, R. J., Snead, L. L., and Ghoniem, N. M., 2008. "Development of advanced blanket performance under irradiation and system integration through JUPITER-II project.” Fusion Engineering and Design 83, 842-849.

Atsumi, H., 2002. "Hydrogen bulk retention in graphite and kinetics of diffusion.” J Nucl Mater 307-311, 1466-1470.

Avila, R. E., Pena, L. A., and Jimenez, J. C., 2010. "Surface desorption and bulk diffusion models of tritium release from $\mathrm{Li}_{2} \mathrm{TiO}_{3}$ and $\mathrm{Li}_{2} \mathrm{ZrO}_{3}$ pebbles.” Journal of Nuclear Materials 405, 244-251.

Baes, C. F., Jr., 1965. The chemistry and thermodynamics of molten salt reactor fluoride solutions, ORNL-P-1428.

Beneš, O., and Konings, R.J.M., 2009. "Thermodynamic properties and phase diagrams of fluoride salts for nuclear applications,” J Fluorine Chem 130, 22-29.

Briggs, R. B. and Korsmeyer, R. B., 1970. "Distribution of tritium in an [molten salt breeder reactor] MSBR,” In Molten-salt reactor program semiannual progress report for period ending February 28, 1970, Oak Ridge National Laboratory, ORNL-4548, 54-57.

Cabage, B., “The short-lived Molten Salt Reactor Experiment is far from forgotten,” https://www.ornl.gov/news/msres-50th.

Calderoni, P., 2008. Measurement of tritium permeation in $\mathrm{FLiBe}\left(2 \mathrm{LiF}-\mathrm{BeF}_{2}\right)$. Fusion Engineering and Design 83, 1331-1334.

Calderoni, P., Sharpe, P., Nishimura, H., and Terai, T., 2009. "Control of molten salt corrosion of fusion structural materials by metallic beryllium.” Journal of Nuclear Materials 386-88, 1102-1106.

Cao, G., 2013. Fluoride-salt-cooled high temperature reactor (FHR) Materials, fuels and components, white paper, University of Wisconsin, Madison.

Christensen, R., Sun, X., Sabharwall, P., Wu, X., and Shi, S., 2016. Tritium Mitigation/Control for Advanced Reactor System. Ohio State University, Columbus.

Cornwell, K. 1971. "The thermal conductivity of molten salts,” J. Phys. D: Applied Physics 4, 441-445.

DOE Handbook, Tritium Handling and Safe Storage, DOE-HDBK-1129-2007, March 2007.

Department of Energy, "Energy Department Announces New Investments in Advanced Nuclear Power Reactors to Help Meet America's Carbon Emission Reduction Goal,” http://www.energy.gov/articles/energy-department-announces-new-investments-advancednuclear-power-reactors-help-meet, January 2016.

Edmonds, P. H., 1985. Jet-ISX-B Beryllium limiter experiment safety analysis report and operational safety requirements, Oak Ridge National Laboratory, ORNL/TM-9512.

Engelmann, U., Glugla, M., Noppel, H. E., Penzhorn, R. D., Willin, E., and Ache, H. J., 1995. Analyticalchemistry in controlled thermonuclear fusion. Journal of Radioanalytical and Nuclear ChemistryArticles 193, 347-356.

Fukada, S. and Morisaki, A., 2006. "Hydrogen permeability through a mixed molten salt of LiF, NaF and KF (FLiNaK) as a heat-transfer fluid.” J Nucl Mater 358, 235-242.

Fukada, S., 2007. "Reaction rate of beryllium with fluorine ion for FLiBe redox control.” J Nucl Mater 367-370, 1190-1196.

Fukada, S. and Mitsuishi, N., 1988. "Hydrogen permeation through duct walls with turbulent-flow," Mem. Fac. Eng. Kyushu Univ.

Fraas and Özişik, 1965. Heat Exchanger Design, New York: Wiley.

Forsberg, C. W., Lam, S., Carpenter, D. M., Whyte, D. G., Scarlat, R., Contescu, C. and Wei, L., 2016. Tritium control and capture in salt-cooled fission and fusion reactors: Status, challenges, and path forward, MIT-ANP-TR-166, May 2016. 
Gainey, B. W., 1976. A review of tritium behavior in [high-temperature gas-cooled reactor] HTGR systems, General Atomics, GA-A13461.

Georgia Institute of Technology, 2014. Integrated approach to fluoride high temperature reactor (FHR) technology and licensing challenges, Proposal for an integrated research project in response to DE-FOA-0000998 (CFDA 81.121).

Grimes, W. R., Cuneo, D. R., Blankenship, F. F., Keilholtz, G. W., Poppenick, H. F., and Robinson, M. T., 1958. "Chemical aspects of molten fluoride salt reactor fuels,” In Fluid Fueled Reactors, etc. J. A. Lane, Addison-Wesley, NY, Chapter 12, 569-594.

Grimes, W. R., 1967. Chemical research and development for the molten-salt breeder reactor, Oak Ridge National Laboratory, ORNL/TM-1853.

Grimes, W. R., 1970. “Molten salt reactor chemistry,” Nuclear Applications and Technology 8(2), 137155.

Holcomb, D., Flanagan, F., et al., Fluoride Salt-Cooled High-Temperature Reactor Technology Development and Demonstration Roadmap, ORNL/TM-2013/401, September 2013

Holcomb, D. E. and Wilson, D. F. 2016. Apparatus and method for stripping tritium from molten salt, US Patent Application US20160019993 A1.

Hubert, T., Schwarz, J., and Oerterl, B., 2006. "Sol-gel alumina coatings on stainless steel for wear protection.” J Sol-Gel Sci \& Technol 38, 179-184.

Huntley, W. R. and Silverman, M. D., 1976. System design description of forced-convection molten-salt corrosion loops MSR-FCL-3 and MSR-FCL-4, Oak Ridge National Laboratory, ORNL/TM-5540.

Ingersoll, D. T., Forsberg, C.W., Ott, L.J., Williams, D. R., Renier, J. P., Wilson, D. F., Ball, S. J., Reid, L., Corwin, R., Del Cul, G. D., Peterson, P. F., Zhao, H., Pickard, P. S., Parma, E. J., and Vernon, M., 2004. Status of preconceptual design of the Advanced High-Temperature reactor (AHTR), Oak Ridge National Laboratory, ORNL/TM-2004/104.

Keiser, J. R., DeVan, J. H., and Manning, D. L., 1977. The corrosion resistance of type 316 stainless steel to $\mathrm{Li}_{2} \mathrm{BeF}_{4}$, Oak Ridge National Laboratory, ORNL/TM-5782.

Keiser, J. R., 1977. Compatibility studies of potential molten-salt breeder reactor materials in molten fluoride salts, Oak Ridge National Laboratory, ORNL/TM-5783.

Khokhlov, V., Ignatiev, V., and Afonichkin, V., 2009. "Evaluating properties of molten salt reactor fluoride mixtures,” J. Fluorine Chem. 130, 30-37.

Lecocq, A., 1974. "Method for preventing tritium contamination of secondary salt and steam in a molten salt reactor," US Patent 3,963,564.

Mays. G. T., Smith, A. N., and Engel, J. R., 1977. Distribution and behavior of tritium in the coolant-salt technology facility, Oak Ridge National Laboratory, ORNL/TM-5759.

Osborne, P. E., Icenhour, A. S., and Del Cul, G. D., 2002. Hydrofluoric acid corrosion study of high-alloy materials, Oak Ridge National Laboratory, ORNL/TM-2002/165.

Petherick, K. 2015. SBMS. Beryllium, https://sbms.ornl.gov/sbms/SBMSearch/subjarea/beryllium/pro2.cfm, updated December 17, 2015. Accessed September 9, 2016.

Petit, A.-T. and Dulong, P. L., 1819. Recherches sur quelques points importants de la théorie de la chaleur. Annales de Chemie et de Physique 10, 395-413.

Petti, D. A., Smolik, G. R., Simpson, M. F., Sharpe, J. P., Anderl, R. A., Fukada, S., Hatano, Y., Hara, M., Oya, Y., Terai, T., Sze, D.-K., and Tanaka, S., 2006. Fusion Engineering and Design, 81, 1439-1449.

Röhrig, H. D., Hecker, R., Blumensaat, J., and Schaefer, 1975. "Studies on the permeation of hydrogen and tritium in nuclear process heat installations," Nuclear Engineering and Design 34, 157-167.

Sawan, M. E. and Sze, D. K., 2003. "Transmutation and production rates of elements in Flibe and Flinabe with impact on chemistry control.” Fusion Science and Technology 44, 64-68.

Scarlat, R. O. and Peterson, P. F., 2014. "The current status of fluoride salt cooled high temperature reactor (FHR) technology and its overlap with [heavy ion fusion] HIF target chamber concepts.” 
Nuclear Instruments \& Methods in Physics Research Section a-Accelerators Spectrometers Detectors and Associated Equipment 733, 57-64.

Shaffer, J. H., 1971. Preparation and handling of salt mixtures for the molten salt reactor experiment, Oak Ridge National Laboratory, ORNL-4616.

Sherman, S. R. and Adams, T. M., 2008. Tritium barrier materials and separation systems for the [Next Generation Nuclear Plant] NGNP. Washington Savannah River Company, WSRC-STI-200800358. August 2008.

Simpson, M. F., Smolik, G. R., Sharpe, J. P., Anderl, R. A., Petti, D. A., Hatano, Y., Hara, M., Oya, Y., Fukada, S., Tanaka, S., Terai, T., and Sze, D.-K., 2006. "Quantitative measurement of berylliumcontrolled redox of hydrogen fluoride in FLiBe.” Fusion Engineering and Design 81, 541-547.

Special Metals Corporation, 2008, Inconel Alloy 600,

www.specialmetals.com/assets/documents/alloys/inconel/inconel-alloy-600.pdf, accessed September 12, 2016.

Sterbentz, J. W., O’Brien, J. E., Anderl, R. A., Smolik, G. R., Petti, D. A., and McCarthy, K. A., 2000, Neutronic and Thermal/Fluid Design and Instrumentation for the FLIQURE Experiment, Idaho National Engineering and Environmental Laboratory, INEEL/EXT-00-01214.

Talbot, J. B. 1976. A study of tritium removal from fusion reactor blankets of molten salt and lithiumaluminum, Oak Ridge National Laboratory, ORNL/TM-5104.

Thoma, R. E., 1972. Chemical aspects of MSRE operations, Oak Ridge National Laboratory, ORNL4658.

Tørklep, K. and Øye, H. A., 1980. "Viscosity of Eutectic LiF-NaF-KF,” J Chem Eng Data 25, 16-17.

U Wisconsin, Massachusetts Institute of Technology, U California Berkeley, IRP, 2013. Fluoride-saltcooled High Temperature Reactor (FHR) Materials, Fuels and Components White Paper. UCBTH-12-003, U Wisconsin, Madison, WI.

Wang, J., Qun, L., Xiang, Q.-Y., and Cao, J.-L., 2016. “Performances of AlN coatings as hydrogen isotopes permeation barriers,” Fusion Engineering and Design 102, 94-98.

Weaver, B. and Wall, W. R., 2007. Tritium Handling and Safe Storage. US Department of Energy.

Williams, D. F., Toth, L. M., and Clarno, K. T., 2006. Assessment of Candidate Molten Salts for the Advanced High-Temperature Reactor (AHTR), Oak Ridge National Laboratory, ORNL-TM2006/12.

World Health Organization, 1990. International Programme on Chemical Safety, Beryllium, Geneva.

Wu, X., Shi, S., Sun, X., Christensen, R., and Sabharwall, P., 2016. Tritium Mitigation and Control for Advanced Reactor System, Nuclear Energy University Programs Report, US Department of Energy, OSU/NE-THL-16-03.

Yannopoulos, L., Jansson, S., Gulbransen, E., 1973. "Yttrium-hydrogen isotope compositions for radiochemical reactions”, US Patent 3716491A.

Zeng, Y. S., 2014. “Apparatus for determining permeability of hydrogen isotopes in molten-salt,” Nuclear Sci and Techniques 25(4), 040602. 

APPENDIX A. FIGURES 



\section{APPENDIX A. FIGURES}

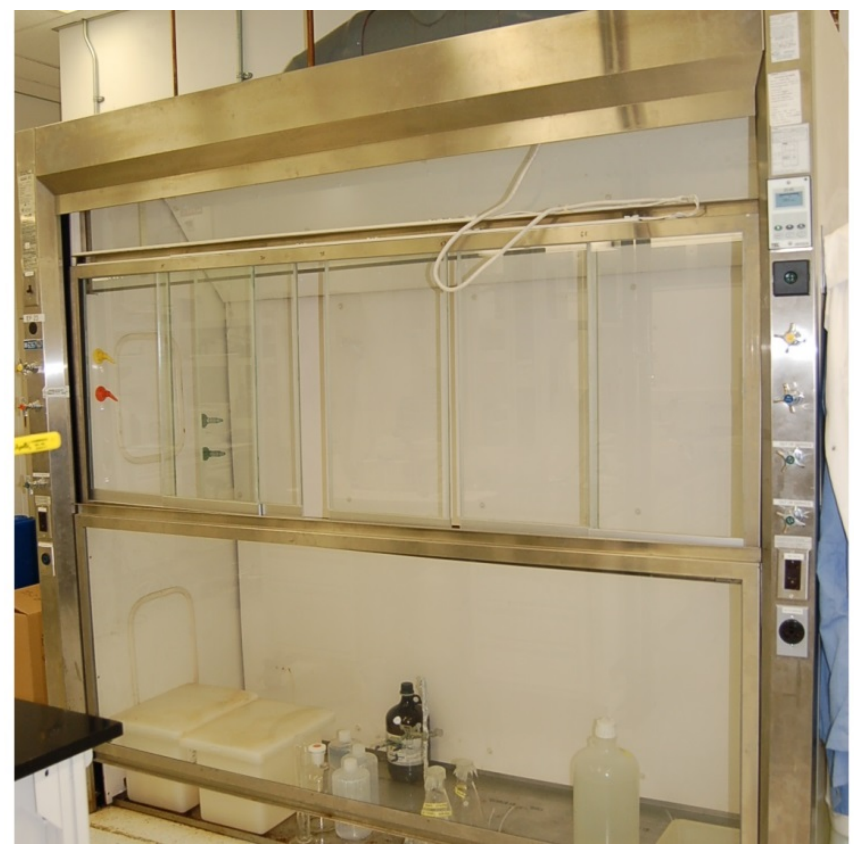

Figure 2. Walk-in hood similar to that proposed for tritium mitigation experiments.

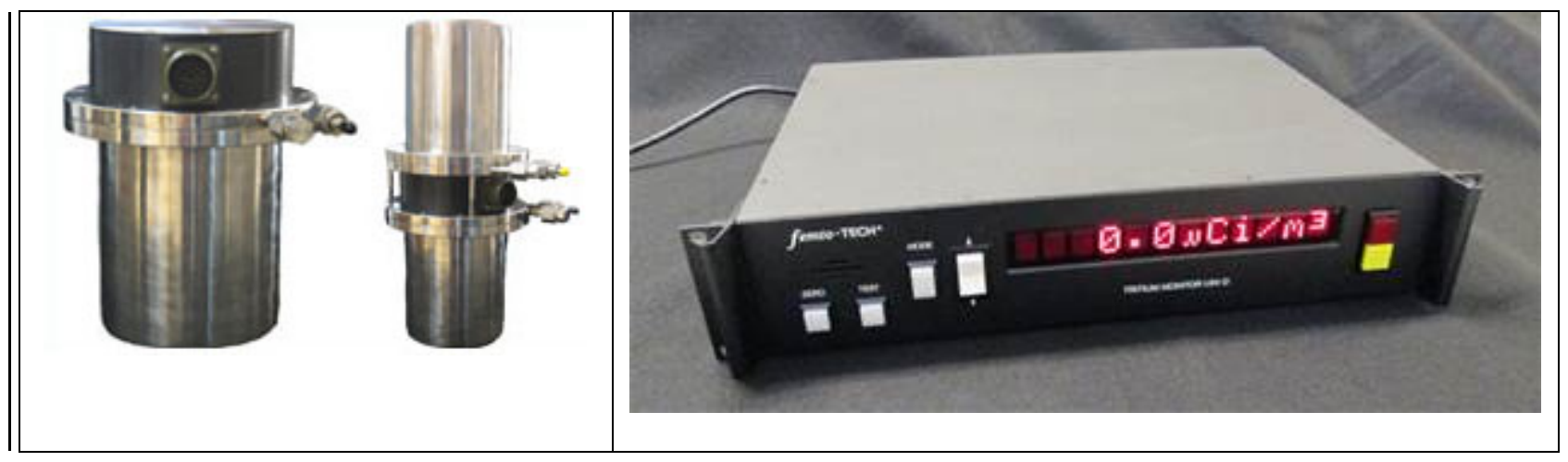

Figure 2. Femto-TECH ion chamber and controller. 


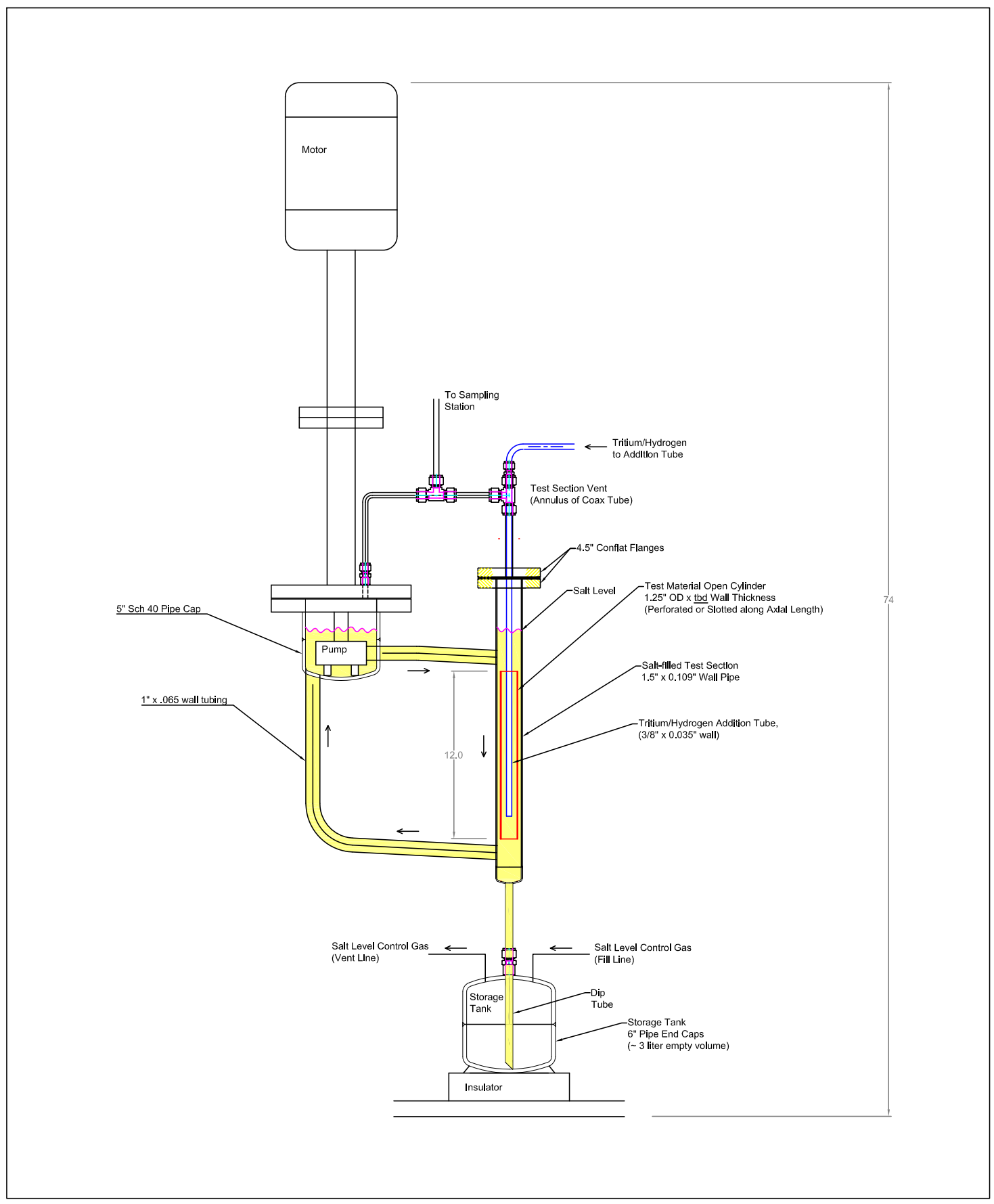

Figure 3. Tritium forced circulation loop concept. 


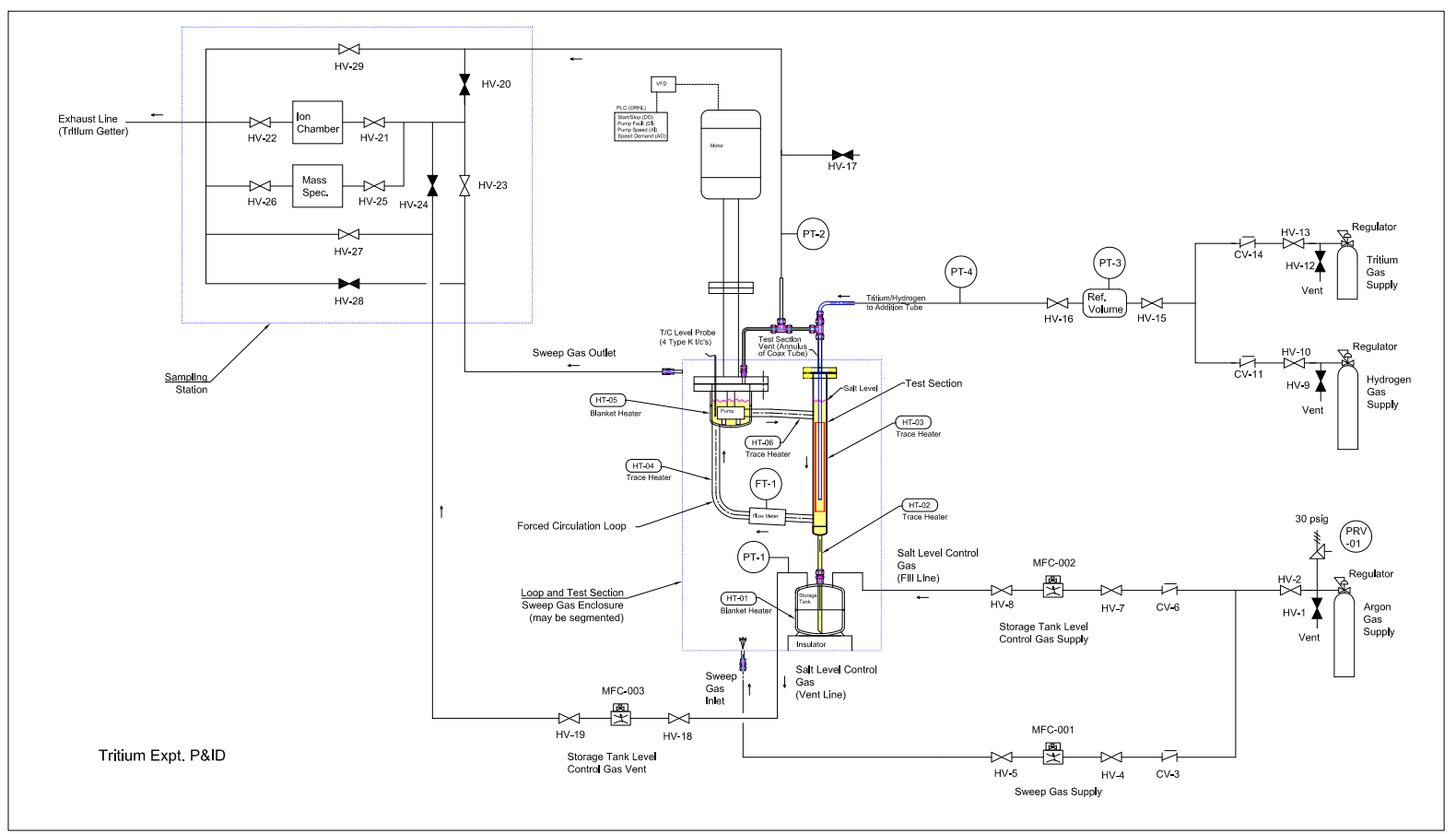

Figure 4. Preliminary tritium loop P\&ID. 


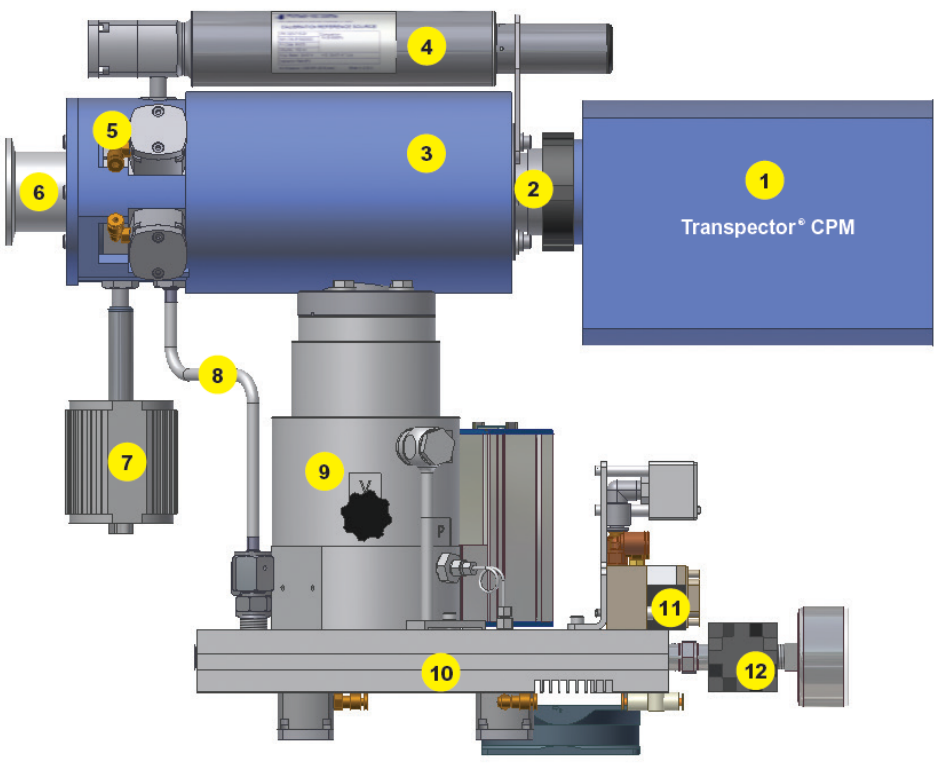

CPM CONFIGURATION KEY

1 CPM electronics

2 CPM sensor

3 Sensor manifold and heater

4 Optional calibration reference

5 HexBlock inlet

6 Process connection(CF40, KF40 or KF25)

7 Process gauge (CDG)

8 Interstage connection for high-pressure applications

9 UHV compound pump

10 Integrated foreline block

11 Valve solenoids

12 Nitrogen regulator (for nitrogen purge and valve operation)

Figure 5. Inficon mass spectrometer. 
APPENDIX B. TABLES 


\section{APPENDIX B. TABLES}

Table 1. Properties of fluorinated molten salts (Williams et al. 2006, Beneš and Konings, 2009) (at $700{ }^{\circ} \mathrm{C}$ unless otherwise noted)

\begin{tabular}{|c|c|c|}
\hline Property & FLiBe & FLiNaK \\
\hline composition (mol\%) & $67 \% \mathrm{LiF}-33 \% \mathrm{BeF}_{2}$ & 46.5\% LiF-11.5\% NaF-42\% KF \\
\hline melting point $\left({ }^{\circ} \mathrm{C}\right)$ & $458-460$ & 454 \\
\hline normal boiling point $\left({ }^{\circ} \mathrm{C}\right)$ & $\begin{array}{l}1,400 \\
\text { (extrapolated from data at } 1100 \text { ) }\end{array}$ & 1,570 \\
\hline liquid density $\left(\mathrm{g} \cdot \mathrm{cm}^{-3}\right) *$ & $\begin{array}{l}2.280-0.000488 \cdot \mathrm{t} \\
1.94 \\
2.1463-0.0004884 \cdot \mathrm{T}(66 \% \mathrm{LiF}, 34 \% \\
\left.\mathrm{BeF}_{2}\right)\end{array}$ & $\begin{array}{l}2.530-0.00073 \cdot \mathrm{t} \\
2.02 \\
2.5793-0.0006204 \cdot \mathrm{T}\end{array}$ \\
\hline vapor pressure $(\mathrm{Pa})$ & $\begin{array}{l}\log _{10} p=11.914-\frac{13003}{T} \\
\left(550-1200^{\circ} \mathrm{C}\right)\end{array}$ & $\begin{array}{l}\log _{10} p=10.748-\frac{10789}{T} \\
\left(550-1200^{\circ} \mathrm{C}\right)\end{array}$ \\
\hline $\begin{array}{l}\text { heat capacity at } 700{ }^{\circ} \mathrm{C} \\
\left(\mathrm{cal} \cdot \mathrm{g}^{-1} \cdot\left({ }^{\circ} \mathrm{C}\right)^{-1}\right)\end{array}$ & $0.577 \pm 0.012$ & $0.45 \pm 0.05$ \\
\hline $\begin{array}{l}\text { Viscosity }(\mathrm{cP}) * \\
\left(\mathrm{~J} \cdot \mathrm{s} \cdot \mathrm{mole}^{-1} \times 10^{7}\right)^{\#}\end{array}$ & $\begin{array}{l}0.0116 \cdot \exp (3755 / \mathrm{T}) \\
5.6 \\
0.818 \text { (Khokhlov et al. 2009) }\end{array}$ & $\begin{array}{l}\text { 0.04·exp(4170/T) } \\
\text { 2.9, } 2.5 \text { (Tørklep and Øye 1980) }\end{array}$ \\
\hline $\begin{array}{l}\text { Thermal conductivity } \\
\left(\mathrm{W} \cdot \mathrm{m}^{-1} \cdot \mathrm{K}^{-1}\right)\end{array}$ & $\begin{array}{l}0.79\left(600^{\circ} \mathrm{C}\right) \\
1.0\left(650^{\circ} \mathrm{C}\right)-1.2\left(750-860^{\circ} \mathrm{C}\right)\end{array}$ & $\begin{array}{l}-1.6044 \cdot \exp (1944 / \mathrm{T}) \\
0.68\left(500^{\circ} \mathrm{C}\right) \\
0.92 \\
\lambda=0.36+5.6 \times 10^{-4} \mathrm{~T}\end{array}$ \\
\hline $\begin{array}{l}\text { Volume expansivity, } \beta \\
\left({ }^{\circ} \mathrm{C}\right)^{-1}\end{array}$ & $2.52 \times 10^{-4}$ & $3.61 \times 10^{-4}$ \\
\hline $\begin{array}{l}\text { Prandtl number } \\
\left(\mathrm{Cp} \cdot \mu \cdot \mathrm{k}^{-1}\right)\end{array}$ & 13.626 & 5.938 \\
\hline $\begin{array}{l}\text { Neutron capture per unit volume } \\
\text { relative to graphite }\end{array}$ & 8 & 90 \\
\hline Moderating ratio $(0.1-10 \mathrm{eV})$ & 60 & 2 \\
\hline
\end{tabular}




\section{Table 2. Transmutation reactions in FLiBe molten salts}

\begin{tabular}{|c|c|c|}
\hline \multicolumn{3}{|c|}{ Be - important at steady state } \\
\hline${ }^{9} \mathrm{Be}$ & $(n, 2 n)$ & $2{ }^{4} \mathrm{He}$ \\
\hline${ }^{9} \mathrm{Be}$ & $(n, t)$ & ${ }^{7} \mathrm{Li}$ \\
\hline${ }^{9} \mathrm{Be}$ & $(n, \alpha)$ & ${ }^{6} \mathrm{He}\left(\mathrm{t}_{1 / 2}=807 \mathrm{~ms}\right) \rightarrow{ }^{6} \mathrm{Li}$ \\
\hline${ }^{9} \mathrm{Be}$ & $(n, \gamma)$ & ${ }^{10} \mathrm{Be}$ \\
\hline \multicolumn{3}{|c|}{ F - less important } \\
\hline${ }^{19} \mathrm{~F}$ & $(n, p)$ & ${ }^{19} \mathrm{O}\left(\mathrm{t}_{1 / 2}=26.9 \mathrm{~s}\right) \rightarrow{ }^{19} \mathrm{~F}$ \\
\hline${ }^{19} \mathrm{~F}$ & $(\mathrm{n}, \mathrm{d})$ & ${ }^{18} \mathrm{O}$ \\
\hline${ }^{19} \mathrm{~F}$ & $(n, t)$ & ${ }^{17} \mathrm{O}$ \\
\hline${ }^{19} \mathrm{~F}$ & $(n, \alpha)$ & ${ }^{16} \mathrm{~N}\left(\mathrm{t}_{1 / 2}=7.13 \mathrm{~s}\right) \rightarrow{ }^{16} \mathrm{O}$ \\
\hline${ }^{19} \mathrm{~F}$ & (n,n’p) & ${ }^{18} \mathrm{O}$ \\
\hline${ }^{19} \mathrm{~F}$ & $\left(n, n^{\prime} \alpha\right)$ & ${ }^{15} \mathrm{~N}$ \\
\hline${ }^{19} \mathrm{~F}$ & $(n, 2 n)$ & ${ }^{18} \mathrm{~F}\left(\mathrm{t}_{1 / 2}=1.83 \mathrm{~h}\right) \rightarrow{ }^{18} \mathrm{O}$ \\
\hline${ }^{19} \mathrm{~F}$ & $(n, \gamma)$ & ${ }^{20} \mathrm{~F}\left(\mathrm{t}_{1 / 2}=11 \mathrm{~s}\right) \rightarrow{ }^{20} \mathrm{Ne}$ \\
\hline \multicolumn{3}{|c|}{${ }^{6} \mathbf{L i}$ - early time production mechanism } \\
\hline${ }^{6} \mathrm{Li}$ & $(n, \alpha)$ & ${ }^{3} \mathrm{H}$ \\
\hline${ }^{6} \mathrm{Li}$ & $(\mathrm{n}, 2 \mathrm{n} \alpha)$ & ${ }^{1} \mathrm{H}$ \\
\hline${ }^{6} \mathrm{Li}$ & (n, n’d) & ${ }^{4} \mathrm{He}$ \\
\hline${ }^{6} \mathrm{Li}$ & $(n, p)$ & ${ }^{6} \mathrm{He}\left(\mathrm{t}_{1 / 2}=807 \mathrm{~ms}\right) \rightarrow{ }^{6} \mathrm{Li}$ \\
\hline${ }^{6} \mathrm{Li}$ & $(n, \gamma)$ & ${ }^{7} \mathrm{Li}$ \\
\hline \multicolumn{3}{|c|}{${ }^{7} \mathbf{L i}$ - steady state } \\
\hline${ }^{7} \mathrm{Li}$ & $\left(n, n^{\prime} \alpha\right)$ & ${ }^{3} \mathrm{H}$ \\
\hline${ }^{7} \mathrm{Li}$ & $(\mathrm{n}, 2 \mathrm{n} \alpha)$ & ${ }^{2} \mathrm{H}$ \\
\hline${ }^{7} \mathrm{Li}$ & $(n, \gamma)$ & ${ }^{8} \mathrm{Li}\left(\mathrm{t}_{1 / 2}=0.84 \mathrm{~ms}\right) \rightarrow{ }^{8} \mathrm{Be} \rightarrow 2{ }^{4} \mathrm{He}$ \\
\hline${ }^{7} \mathrm{Li}$ & $(\mathrm{n}, \mathrm{d})$ & ${ }^{6} \mathrm{He}\left(\mathrm{t}_{1 / 2}=807 \mathrm{~ms}\right) \rightarrow{ }^{6} \mathrm{Li}$ \\
\hline${ }^{7} \mathrm{Li}$ & $(n, 2 n)$ & ${ }^{6} \mathrm{Li}$ \\
\hline
\end{tabular}


Table 3. Permeability of tritium through selected materials (Christensen et al. 2016)

\begin{tabular}{lllll}
\hline \multicolumn{1}{c}{ Material } & \multicolumn{1}{c}{ Solubility } & \multicolumn{1}{c}{ Diffusivity } & \multicolumn{1}{c}{ Permeability } & \multicolumn{1}{c}{ Source } \\
\hline & $\begin{array}{l}\mathrm{mol} / \mathrm{m}^{3}-\mathrm{Pa} \\
\text { or mol} / \mathrm{m}^{3}-\mathrm{Pa}^{0.5}\end{array}$ & $\mathrm{~m}^{2} / \mathrm{s}$ & $\begin{array}{l}\mathrm{mol} / \mathrm{m}-\mathrm{s}-\mathrm{Pa} \\
\text { or mol} / \mathrm{m}-\mathrm{s}-\mathrm{Pa}^{0.5}\end{array}$ & \\
FLiNaK & $5.66 \mathrm{e}-09$ & $8.64 \mathrm{e}-10$ & $4.89 \mathrm{e}-18$ & (Fukada 2007) \\
FLiBe & $1.04 \mathrm{e}-03$ & $5.177 \mathrm{e}-09$ & $5.38 \mathrm{e}-12$ & (Simpson 2006) \\
Palladium & $5.30 \mathrm{e}-02$ & $1.75 \mathrm{e}-08$ & $9.27 \mathrm{e}-10$ & (Calderoni 2008) \\
Nickel & $2.47 \mathrm{e}-01$ & $3.76 \mathrm{e}-09$ & $9.3 \mathrm{e}-10$ & \\
Stainless steel & $9.82 \mathrm{e}-02$ & $1.66 \mathrm{e}-09$ & $4.14 \mathrm{e}-12$ & \\
Graphite & $4.56 \mathrm{e}-04$ & $3.3 \mathrm{e}-10$ & $1.5 \mathrm{e}-13$ & (Atsumi 2002) \\
Air & & $6.10 \mathrm{e}-05$ & & (Fukada 2006) \\
\hline
\end{tabular}


Table 4. Tritium permeation barriers (University of Wisconsin et al. 2013)

\begin{tabular}{llc}
\hline \multicolumn{1}{c}{ Barrier } & \multicolumn{1}{c}{ Base metal } & \multicolumn{1}{c}{$\begin{array}{c}\text { Permeability } \\
\text { reduction factors }\end{array}$} \\
\hline $\mathrm{Al}_{2} \mathrm{O}_{3}$ & $\begin{array}{l}\text { SS316, manet, } * \mathrm{TZM}, \\
\text { Ni, Hastelloy-X }\end{array}$ & 10 to $>10,000$ \\
$\mathrm{TiC}, \mathrm{TiN}, \mathrm{TiO}_{2}$ & SS316, manet, TZM, Ti & 3 to $>10,000$ \\
$\mathrm{Cr}_{2} \mathrm{O}_{3}$ & SS316 & $10-100$ \\
$\mathrm{Si}$ & steel & 10 \\
$\mathrm{BN}$ & 304SS & 100 \\
$\mathrm{~N}$ & Fe & $10-20$ \\
$\mathrm{Er}_{2} \mathrm{O}_{3}$ & steel & $40-700$ \\
\hline$*$ martensitic steel & &
\end{tabular}


Table 5. U24-D control unit specifications

Power: $\quad$ 100-125 VAC, 50-60 Hz (built-in filter)

Fusing: $\quad 2$ amp line fuses in power entry/filter module of control unit; both hot and neutral sides of the powerline fused

Display: Custom 12-character red light-emitting diode matrix display, readable at $15.4 \mathrm{~m}$ (50 feet)

Zero check: Electronic zero test, push-button with display on front

Zero adjust: Digital zero adjust, push-button switch plus zero adjust and digital panel meter display, to be performed with zero check

Instrument Functional check of entire electrometer, signal conditioning and

test: readout electronics, push-button switch activated and display of $13,000 \pm 390$

Alarms: $\quad$ Two audio/visual alarms with acknowledge and automatic reset; set points are independent and adjustable throughout both ranges

Alarm $\quad$ Automatic 90-second alarm lockout on power up and zero
lockout:

Analog Linear output proportional to tritium concentration, range outputs: indicator, high and low alarm indicators and fault indicator, optional logarithmic output

Data All instrument settings (alarm settings, offset, etc.) retained in storage: electrically erasable programmable read-only memory (EEPROM)

Temperature Electronics : $0-50{ }^{\circ} \mathrm{C}$

range: $\quad$ Note: concentration measurement is a function of temperature through pressure volume temperature (PVT) gas law

Humidity: $\quad 0 \%$ to $95 \%$ r.h. noncondensing

Installation: Ion chamber and control unit can be located up to $307 \mathrm{~m}$ (1,000 feet) apart without degradation of signal

$8.9 \mathrm{~cm}$ (3.5 in) high $\times 42.5 \mathrm{~cm}$ (16.75 in) wide; $48.3 \mathrm{~cm}$ (19-in)

Dimensions: with handle/rack mount hardware $\times 30.5$ cm (12 in) deep (not including space for cable routing)

Weight: $\quad 5.4$ kg (12 lbs.); shipping, 7.7 kg (17 lbs.) 
Table 6. Comparison of GB and PP flow through Femto-Tech ion chambers

\begin{tabular}{|c|c|c|c|c|}
\hline $\begin{array}{l}\text { Ion chamber } \\
\text { type }\end{array}$ & $\begin{array}{c}\text { Low } \\
\text { concentration } \\
\text { stack } \\
\text { monitoring }\end{array}$ & $\begin{array}{c}\text { High } \\
\text { concentration } \\
\text { stack } \\
\text { monitoring }\end{array}$ & $\begin{array}{c}\text { Model } \\
\text { number }\end{array}$ & Description \\
\hline $\begin{array}{l}\text { GB - flow } \\
\text { through }\end{array}$ & $\checkmark$ & & 224GB & $\begin{array}{l}2 \text { liter (1800 cc active) } \\
\text { Low level ion chamber } \\
\text { Range } 1: 0 \text { to } 20 \mathrm{mCi} / \mathrm{m} 3 \\
(0 \text { to } 740 \mathrm{MBq} / \mathrm{m} 3) \\
\text { Range } 2: 0 \text { to } 20 \mathrm{Ci} / \mathrm{m} 3 \\
(0 \text { to } 740 \mathrm{GBq} / \mathrm{m} 3)\end{array}$ \\
\hline $\begin{array}{l}\text { PP - flow } \\
\text { through }\end{array}$ & & $\checkmark$ & $\begin{array}{l}\text { 224PP/ } \\
\text { New Model \#: } \\
\text { 2524PP }\end{array}$ & $\begin{array}{l}\text { Parallel plate } 180 \text { cc ( } 25 \text { cc active) } \\
\text { High level ion chamber } \\
\text { Range } 1: 0 \text { to } 20 \mathrm{Ci} / \mathrm{m} 3 \\
(0 \text { to } 740,000 \mathrm{~Bq} / \mathrm{m} 3) \\
\text { Range } 2: 0 \text { to } 20,000 \mathrm{Ci} / \mathrm{m} 3 \\
(0 \text { to } 740,000,000 \mathrm{~Bq} / \mathrm{m} 3)\end{array}$ \\
\hline
\end{tabular}


Table 7. Femto-TECH ion chamber system types, cost, and quantities

\begin{tabular}{rcrl}
\hline \multicolumn{1}{c}{ Type } & Quantity & Cost & \multicolumn{1}{c}{ Anticipated requirement } \\
\hline 224DU-U24-D-CA6 & 2 & $\$ 40,000.00$ & Loop R\&D \\
224GB-U24-D-CA6 & 1 & $20,000.00$ & Room monitor \\
224GB-U24-D-CA6 & 1 & $20,000.00$ & Fume hood stack monitoring \\
\hline Totals: & $\mathbf{4}$ & $\mathbf{\$ 8 0 , 0 0 0 . 0 0}$ & \\
\hline
\end{tabular}


Table 8. Specifications for Inficon mass spectrometer

\section{SPECIFICATIONS}

\begin{tabular}{|c|c|c|c|}
\hline & CPM & CPM & CPM \\
\hline Mass Range & 1 to $100 \mathrm{amu}$ & 1 to $200 \mathrm{amu}$ & 1 to $300 \mathrm{amu}$ \\
\hline Peak Width@ 10\% Peak Maximum & \multicolumn{3}{|c|}{$<1 \mathrm{amu}$} \\
\hline Ion Source Type & \multicolumn{3}{|c|}{ Closed Ion Source } \\
\hline Total Pressure Range $^{1}$ & \multicolumn{3}{|c|}{$5 \mathrm{E}-7$ to $1 \mathrm{E}-3$ Torr (6.6E-7 to $1.3 \mathrm{E}-3 \mathrm{mbar}$ ) } \\
\hline Total Pressure Accuracy ${ }^{2}$ & \multicolumn{3}{|c|}{ $\pm 25 \% 1 \mathrm{E}-6$ to $1 \mathrm{E}-3$ Torr (1.3E-6 to $1.3 \mathrm{E}-3 \mathrm{mbar})$} \\
\hline Maximum lon Source Operating Pressure ${ }^{3}$ & \multicolumn{3}{|c|}{ 1E-3 Torr (1.3E-3 mbar) } \\
\hline Nominal Ion Source Operating Pressure ${ }^{4}$ & \multicolumn{3}{|c|}{ 2E-4 Torr (2.6E-4 mbar) } \\
\hline $\begin{array}{l}\text { System Operating Pressure } \\
\text { (with orifices/capillary) }\end{array}$ & \multicolumn{3}{|c|}{ 1E-8 Torr (1.3E-8 mbar) to 1.5 atmospheres } \\
\hline Multiplier Gain @ 1225 Volts $^{5}$ & \multicolumn{3}{|c|}{$>10,000$} \\
\hline \multirow[t]{2}{*}{$\begin{array}{l}\text { Sensitivity } \\
\text { @ Low Emission, FC mode }\end{array}$} & $>4.0 \mathrm{E}-6 \mathrm{amps} / \mathrm{Torr}$ & $>2.0 \mathrm{E}-6 \mathrm{amps} / \mathrm{Torr}$ & $>1.0 \mathrm{E}-6 \mathrm{amps} / \mathrm{Torr}$ \\
\hline & (>3E-6 amps/mbar) & (>1.5E-6 amps/mbar) & (>7.6E-7 amps/mbar) \\
\hline \multirow[t]{2}{*}{ @ High Emission, FC mode } & $>2.0 \mathrm{E}-5 \mathrm{amps} /$ Torr & $>1.0 \mathrm{E}-5 \mathrm{amps} / \mathrm{Torr}$ & $>5.0 \mathrm{E}-6 \mathrm{amps} /$ Torr \\
\hline & (>1.5E-5 amps/mbar) & (>7.6E-6 amps/mbar) & (>3.8E-6 amps/mbar) \\
\hline Minimum Detectable Partial Pressure ${ }^{6}$ & $\begin{array}{c}\text { 1.0E-13 Torr } \\
\text { (1.3E-13 mbar) }\end{array}$ & $\begin{array}{c}\text { 2.0E-13 Torr } \\
(2.6 \mathrm{E}-13 \text { mbar })\end{array}$ & $\begin{array}{c}\text { 4.0E-13 Torr } \\
\text { (5.3E-13 mbar) }\end{array}$ \\
\hline Abundance Sensitivity $^{7}$ & $<5 \mathrm{ppm}$ & $<10 \mathrm{ppm}$ & $<100 \mathrm{ppm}$ \\
\hline Zero Blast $^{8}$ & $<2 \mathrm{ppm}$ & $<25 \mathrm{ppm}$ & $<200$ ppm \\
\hline Detection Limit ${ }^{9}$ & $<1 \mathrm{ppm}$ & $<2 \mathrm{ppm}$ & $<4 \mathrm{ppm}$ \\
\hline Linearity $^{10}$ & & $\pm 20 \%$ & \\
\hline Minimum Background Pressure & & $<1.0 \mathrm{E}-8$ Torr $(<1.3 \mathrm{E}-8 \mathrm{mbar})$ & \\
\hline $\begin{array}{l}\text { Maximum Sensor and Inlet } \\
\text { Operating Temperature }\end{array}$ & & $150^{\circ} \mathrm{C}$ & \\
\hline \multicolumn{2}{|c|}{$\begin{array}{l}1 \text { Pressure reading at low emission using total pressure lens } \\
2 \text { Total pressure accuracy at low emission } \\
3 \text { Maximum ion source operating pressure at low emission } \\
\text { (filament turn-off threshold) } \\
4 \text { 2E- } 4 \text { Torr in the closed ion source will produce about } 1 \mathrm{E}-5 \text { Torr in } \\
\text { the quadrupole region }\end{array}$} & \multicolumn{2}{|c|}{$\begin{array}{l}5 \text { Minimum EM gain at maximum EM voltage } \\
6 \text { MDPP with EM on at } 10,000 \text { gain and } 1 \text {-second dwell time } \\
7 \text { Mass } 40 \text { contribution onto } 41 \text { amu } \\
8 \text { Zero blast contribution onto } 2 \text { amu } \\
9 \text { Minimum detectable concentration with krypton in air at a } 1 \text {-second dwell } \\
\text { 10 Linearity at low emission at } 0.1 \text { to } 2 \text { times the nominal orifice pressure }\end{array}$} \\
\hline \multicolumn{4}{|l|}{$C \epsilon$} \\
\hline
\end{tabular}

